NBER WORKING PAPER SERIES

\title{
THE USE AND MISUSE OF INCOME DATA AND EXTREME POVERTY IN THE UNITED STATES
}

\author{
Bruce D. Meyer \\ Derek Wu \\ Victoria R. Mooers \\ Carla Medalia \\ Working Paper 25907 \\ http://www.nber.org/papers/w25907
NATIONAL BUREAU OF ECONOMIC RESEARCH
1050 Massachusetts Avenue
Cambridge, MA 02138 \\ May 2019
}

Any opinions and conclusions expressed herein are those of the author(s) and do not necessarily represent the views of the U.S. Census Bureau, the U.S. Social Security Administration, any agency of the federal government, or the National Bureau of Economic Research. This paper meets all of the U.S. Census Bureau's Disclosure Review Board (DRB) standards and has been assigned DRB approval numbers CBDRB-FY18-324 and CBDRB-FY19-173. We are grateful for comments from John Creamer, Liana Fox, David Johnson, Robert Moffitt, Laryssa Mykyta, Austin Nichols, Trudi Renwick, Jonathan Rothbaum, Luke Shaefer, James Spletzer, Laura Wheaton, Scott Winship, James Ziliak, and participants in seminars at the American Enterprise Institute, Brookings Institution, NBER Public Economics group, PAA Annual Meeting, Society of Government Economists, University of California, Berkeley, University of California, Irvine, University of California, Santa Cruz, University of Chicago Booth School of Business, University of Michigan, University of Wisconsin-Madison (Institute for Research on Poverty), and Yale University (Conference in Honor of Joseph Altonji). We also appreciate the support of the Alfred P. Sloan Foundation, the Russell Sage Foundation, the Charles Koch Foundation, and the SSA through grant \#5-RRC08098400-10 to the NBER as part of the SSA Retirement Research Consortium.

NBER working papers are circulated for discussion and comment purposes. They have not been peer-reviewed or been subject to the review by the NBER Board of Directors that accompanies official NBER publications.

(C) 2019 by Bruce D. Meyer, Derek Wu, Victoria R. Mooers, and Carla Medalia. All rights reserved. Short sections of text, not to exceed two paragraphs, may be quoted without explicit permission provided that full credit, including (C) notice, is given to the source. 
The Use and Misuse of Income Data and Extreme Poverty in the United States

Bruce D. Meyer, Derek Wu, Victoria R. Mooers, and Carla Medalia

NBER Working Paper No. 25907

May 2019

JEL No. C42,C81,I32,I38

\begin{abstract}
$\underline{\text { ABSTRACT }}$
Recent research suggests that rates of extreme poverty, commonly defined as living on less than $\$ 2 /$ person/day, are high and rising in the United States. We re-examine the rate of extreme poverty by linking 2011 data from the Survey of Income and Program Participation and Current Population Survey, the sources of recent extreme poverty estimates, to administrative tax and program data. Of the 3.6 million non-homeless households with survey-reported cash income below $\$ 2 /$ person/day, we find that more than $90 \%$ are not in extreme poverty once we include inkind transfers, replace survey reports of earnings and transfer receipt with administrative records, and account for the ownership of substantial assets. More than half of all misclassified households have incomes from the administrative data above the poverty line, and several of the largest misclassified groups appear to be at least middle class based on measures of material wellbeing. In contrast, the households kept from extreme poverty by in-kind transfers appear to be among the most materially deprived Americans. Nearly $80 \%$ of all misclassified households are initially categorized as extreme poor due to errors or omissions in reports of cash income. Of the households remaining in extreme poverty, $90 \%$ consist of a single individual. An implication of the low recent extreme poverty rate is that it cannot be substantially higher now due to welfare reform, as many commentators have claimed.
\end{abstract}

Bruce D. Meyer

Harris School of Public Policy

University of Chicago

1307 E 60th Street

Chicago, IL 60637

and NBER

bdmeyer@uchicago.edu

Derek Wu

Harris School of Public Policy

University of Chicago

1307 E 60th Street

Chicago, IL 60637

derekwu@uchicago.edu
Victoria R. Mooers

Harris School of Public Policy

University of Chicago

1307 E 60th Street

Chicago, IL 60637

victoriamooers@uchicago.edu

Carla Medalia

U.S. Census Bureau

4600 Silver Hill Road

Washington, DC 20233

carla.medalia@census.gov

A data appendix is available at http://www.nber.org/data-appendix/w25907 


\section{Introduction}

There are reasons to be simultaneously concerned and skeptical about recent reports of high and rising rates of extreme poverty in the United States. Several distinguished scholars have argued that millions of Americans - many of them children - live on less than a few dollars per day. Other researchers have reported high rates of "disconnected" people, defined as those with neither earnings nor government benefits. Relying predominantly on survey reports of income, both groups claim that these problems have been rising sharply over time. On the other hand, researchers have long contended that survey reports in the tails of the income distribution have a disproportionate share of errors. Some of these scholars have pointed to evidence of increased underreporting of income in household surveys or conflicting evidence from consumption data. This paper addresses these questions by bringing to bear a combination of previously under-utilized survey data and newly linked administrative data. These data allow us to re-examine rates of extreme poverty and shed light on other questions, including the targeting of in-kind transfers, the effects of welfare reform, and the measurement of poverty.

Focusing on 2011 data from the Survey of Income and Program Participation (SIPP), we show that more than $90 \%$ of the 3.6 million households with survey-reported cash income below $\$ 2 /$ person/day are misclassified. Our methodology first implements a series of adjustments using only the survey data. We begin by reclassifying households as not in extreme poverty if they received sufficiently high amounts of in-kind transfers including SNAP (Supplemental Nutrition Assistance Program), the Special Supplemental Nutrition Program for Women, Infants, and Children (WIC), and housing assistance. We then account for those who reported hours worked for pay but underreported earnings (failing to report any earnings in the vast majority of cases) or who possessed substantial assets. To further examine households not captured by the survey-only adjustments, we replace survey reports of earnings, asset income, retirement distributions, Old-Age, Survivors, and Disability Insurance (OASDI), Supplemental Security Income (SSI), SNAP, and housing assistance with values from linked administrative tax and program data and also account for the Earned Income Tax Credit (EITC).

In the end, our best estimate of the extreme poverty rate is $0.24 \%$ among households and $0.11 \%$ among individuals, with $90 \%$ of the remaining extreme poor households made up of single individuals. We suspect the true extreme poverty rate is lower, given the evidence of survey underreporting for many income sources - like unemployment insurance, Temporary Assistance for 
Needy Families (TANF), workers' compensation, veterans' benefits, and informal earnings - for which we have not been able to incorporate administrative data. Our results are robust to a number of modifications. For example, very few households with survey-reported incomes over \$2/person/day fall below \$2/person/day after applying the administrative data and removing imputed earnings. Excluding imputed hours from the corrections for underreported earnings also yields trivial impacts. In addition, according to the administrative data alone, nearly $80 \%$ of the misclassified households overall are initially categorized as extreme poor due to errors or omissions in cash reports of earnings, asset income, retirement income, OASDI, SSI, or the EITC. As a result, in-kind transfers play a secondary role. Replicating the analysis with the 2012 Current Population Survey Annual Social and Economic Supplement (CPS ASEC), we estimate that only 0.18\% of households and $0.13 \%$ of individuals are in extreme poverty for the 2011 calendar year. These estimates from the two surveys are remarkably similar to rates that researchers have calculated using consumption data, ${ }^{1}$ suggesting that improved measures of income can reconcile past inconsistencies between income and consumption measures of poverty.

One of this paper's key methodological advances is the use of multiple sources of administrative and survey data to validate the survey-only adjustments. As the survey-only adjustments alone can account for $78 \%$ of the total decrease in extreme poverty that we calculate, showing that they are confirmed by other sources makes the evidence compelling. For the groups reclassified due to underreported earnings and substantial assets, we find that $72-93 \%$ of these households have incomes from the administrative data above the extreme poverty threshold and 47$65 \%$ have incomes above the poverty line, depending on the subgroup. Using detailed information from SIPP topical modules, we find that these groups have material well-being levels (based on measures of material hardship, appliance ownership, and housing quality) that are similar to the U.S. average. They are also comparable to the average household on a host of other survey-reported dimensions, such as years of education, health insurance coverage (especially private coverage), and occupation.

Accordingly, the preponderance of evidence suggests that the households reclassified by underreported earnings and substantial assets have survey incomes that are likely to be gross errors. These results provide a potential explanation for the lack of a strong correlation found by several

\footnotetext{
${ }^{1}$ See Chandy and Smith (2014) and Hall and Rector (2018).
} 
studies between income poverty and material hardship. ${ }^{2}$ In contrast, the households reclassified due to receipt of in-kind transfers appear to be significantly worse off than the official poor on multiple dimensions of well-being, implying that these benefits are well targeted to the needy. These results are consistent with past findings that individuals excluded from the poverty rolls under the Census Bureau's Supplemental Poverty Measure (which incorporates in-kind transfers into income and raises some recipients above the poverty line) appear worse off, on average, than the official income poor. ${ }^{3}$

It is important to keep in mind that our best estimate of the extreme poverty rate is not necessarily a final estimate for the population. The SIPP excludes homeless individuals and institutionalized populations (such as those living in nursing care facilities and prisons) from its survey frame, meaning our estimates of extreme poverty are understated if substantial numbers of the homeless and other institutionalized populations are in extreme poverty. We should emphasize, however, that the literature reporting high rates of extreme poverty has relied on survey data that exclude the homeless and institutionalized. If anything, these caveats further highlight the imperfect ability of most survey data, when analyzed at face value, to identify the extreme poor.

While this paper demonstrates that the rate of extreme poverty in the United States is substantially lower than what has been reported, we do not contend that there is little deprivation in the United States. Rather, we argue that focusing on such low-income thresholds as $\$ 2 /$ person/day in the United States is likely to yield a group filled with more gross errors than households that are truly impoverished. For instance, nearly $50 \%$ of the hou seholds classified as extreme poor based on survey-reported cash have incomes above the poverty line in our administrative data sources (which we know to be incomplete). Moreover, the households receiving means-tested in-kind transfers who appear to be among the most materially deprived Americans - are almost all not in extreme poverty simply by virtue of the extreme poverty income thresholds being lower than benefit amounts. Among the households that appear to be truly extreme poor, and therefore disconnected from work or the safety net, the vast majority consist of a single childless individual. Contrasting sharply with the focus in the literature on extreme poverty among households with children, this finding is consequential from a policy perspective as eligibility for programs is often dependent on household composition.

\footnotetext{
${ }^{2}$ See, for example, Mayer and Jencks (1989), Meyer and Sullivan (2003, 2011, 2012), and Short (2005).

${ }^{3}$ See Meyer and Sullivan (2012) and Fox and Warren (2018).
} 
While our main approach begins with households that are below \$2/person/day in the survey reports, as a robustness check we start from the full sample, combining the survey and administrative data. In this alternative analysis, we rely on some of the survey reports in the case of earnings and housing assistance. We do this because our source of administrative earnings data turns out to be incomplete, missing categories of earnings and individuals without work authorization. The housing data are incomplete as well, missing several million subsidized housing units that are not part of the main programs administered by the Department of Housing and Urban Development(HUD). For all other income sources, we simply replace the survey reports with the administrative records. The results using this approach do not differ appreciably from our main results. We also confirm that our main results hold at a cutoff of $\$ 4 /$ person/day, for shorter and longer time intervals, and when imputed values of hours or income components are set to zero.

More generally, this paper is one of the first from an unprecedented new project that assembles and links survey and administrative data on income, program receipt, and closely related information (Medalia, Meyer, O'Hara, and Wu 2019). The project's goals include 1) improving household surveys and statistically based tax administration and 2) better understanding poverty, inequality, and the effects of government transfers. We initially focus on extreme poverty in this paper because the results are so stark and they demonstrate the capacity of the linked data to change our understanding of poverty. There is great value in linking survey and administrative data, even relative to methods that attempt to formally adjust for misreporting within the survey. Two studies have found that sophisticated adjustments like the Urban Institute's Transfer Income Model (TRIM) allocate SNAP and TANF benefits to those with very different survey incomes than true recipients, likely biasing any poverty estimates. ${ }^{4}$

The remainder of the paper is structured as follows. ${ }^{5}$ Section II reviews the literature on extreme poverty and discusses why the rates using survey-reported cash income are so high. Section III describes the survey and administrative data and the process used to link them. Section IV discusses the methodology used to correct for errors in income reports. Section $\mathrm{V}$ describes the main results from the SIPP, and Section VI describes results validating the survey-only corrections and adjustments. Section VII replicates the analysis for the CPS and compares it to the SIPP, and Section VIII presents the results of robustness checks and additional caveats. Section IX concludes.

\footnotetext{
${ }^{4}$ See Shantz and Fox (2018) and Mittag (2019).

${ }^{5}$ See Table 1 for a list of abbreviations used throughout the paper.
} 


\section{Literature}

\section{Past Claims of Extreme Poverty and Conflicting Evidence}

In a series of papers and a best-selling book, Edin and Shaefer document the prevalence of extreme poverty, which they define as having cash income less than $\$ 2 /$ person/day. Using Wave 9 of the 2008 SIPP Panel, Shaefer and Edin (2013) find that 4.3\% of all non-elderly households with children (constituting 1.65 million households and 3.55 million children) lived in extreme poverty in a given month in mid-2011. ${ }^{6}$ Using the 2012 CPS ASEC adjusted using the TRIM, Shaefer and Edin (2017) contend that 1.3 million children (1.8\% of all children) lived under $\$ 2 /$ day based on annual cash income during the 2011 calendar year. ${ }^{7}$ Combining quantitative analyses with ethnographic evidence on the day-to-day lives of the extreme poor, Edin and Shaefer (2015) further shed light on the deprivation faced by such households. Concomitantly, Deaton (2018) uses survey data from the CPS to assert that 5.3 million individuals in the United States lived under $\$ 4 /$ day in income after taxes and in-kind transfers during the 2015 calendar year. These striking numbers have received a great deal of attention in the policymaking process and the press, ${ }^{8}$ and they were featured in a prominent United Nations report on the state of poverty in the United States (United Nations 2018).

A related literature has arisen around the plight of "disconnected" individuals and families, who are defined as having little to no earnings and little or no government benefits (usually cash welfare). Most of these studies focus on single mothers. Turner, Danziger, and Seefeldt (2006) use survey data from the Women's Employment Study and find that 9\% of single mothers who received cash welfare in February 1997 became disconnected for at least a quarter of the following 79 months (following welfare reform in 1996). Using data from the SIPP and CPS, Blank and Kovak (2009) find that more than $20 \%$ of single mothers who live below twice the official poverty line in the mid2000s have no annual earnings or welfare receipt. These high rates of disconnected single mothers are echoed in Loprest (2011) and Loprest and Nichols (2011), who also utilize the SIPP.

\footnotetext{
${ }^{6}$ We begin our empirical work by replicating these numbers.

${ }^{7}$ Even though Shaefer and Edin examine reference year 2011 in both of their papers, the counts of children in extreme poverty differ rather dramatically. We think this difference is due to a few reasons. First, the higher number using the SIPP is based on the fourth reference month of a wave, rather than the monthly average in a wave. Second, as we discuss in Section VII, the SIPP appears to have a non-trivial number of households with zero earnings but positive reports of hours worked for pay - an inconsistency that does not appear in the CPS. Finally, the lower CPS number relies on the Urban Institute's TRIM micro-simulation model to adjust for underreporting of cash transfers in the survey. ${ }^{8}$ For example, see https://www.washingtonpost.com/news/wonk/wp/2018/06/25/trump-team-rebukes-u-n-saying-itoverestimates-extreme-poverty-in-america-by-18-million-people/?utm_term=.1f7ba77d349a.
} 
Importantly, a number of these studies argue that rates of extreme poverty and disconnectedness have risen greatly over time in response to welfare reform. Shaefer and Edin (2013) calculate that the number of households with children in extreme poverty grew by $159 \%$ between 1996 and 2011. This rate of increase snowballs to 748\% between 1995 and 2012 after using TRIM to adjust for underreporting in the CPS, with Shaefer and Edin (2017) attributing the growth entirely to cuts in cash welfare. Blank and Kovak (2009) also find that the rate of disconnected single mothers nearly doubled between 1995 and 2005 using the CPS, and Loprest and Nichols (2011) calculate a similar increase in the share of disconnected single mothers between 1996 and the 2004-2008 period.

At the same time, another literature provides evidence at odds with the results in Shaefer and Edin $(2013,2017)$ and related papers on disconnectedness. Some studies improve the measurement of income by including in-kind transfers and attempting to adjust for survey underreporting. Winship (2016) re-examines rates of extreme poverty by applying a number of adjustments to reported cash income in the CPS, which include incorporating in-kind transfers (non-medical and medical benefits are separated), taxes and tax credits, and a less biased price index (the Personal Consumption Expenditures (PCE) deflator) than the Consumer Price Index for All Urban Consumers (CPI-U). ${ }^{9}$ Winship also uses TRIM3 to correct for underreporting of various transfers and divides household income by an equivalence scale to better account for resource sharing. Winship finds that the adjusted rates of extreme poverty have fallen since welfare reform to approximately $0.1 \%$ among all children and closer to $0.01 \%$ among children of single mothers in 2012. Using also the CPS, Brady and Parolin (2018) calculate that $0.40 \%$ of individuals lived in households with incomes less than $\$ 2 /$ person/day in 2015, after accounting for taxes and transfers (including SNAP), correcting for underreporting of TANF and SSI with TRIM, and accounting for hou sehold size. Parolin and Brady (2018) employ a similar methodology (but additionally adjust for SNAP underreporting using TRIM) to find that $0.08 \%$ of children lived in households with incomes less than $\$ 2 /$ person/day in 2015.

Rather than relying on survey-reported cash income to measure extreme and deep poverty, other studies focus on measures of consumption or hardship. In an early paper, Mayer and Jencks (1989) find that $43 \%$ of a sample of Chicagoans surveyed in the mid-1980s with incomes below the

\footnotetext{
${ }^{9}$ Both the Federal Reserve's Federal Open Market Committee and the Congressional Budget Office use the PCE Deflator rather than the CPI-U to calculate inflation, because the former suffers less from a series of biases that plague the latter (Congressional Budget Office 2012, Bullard 2013).
} 
official poverty line reported expenditures on food, housing, and medical care that exceeded their incomes. For disadvantaged single mothers at the $10^{\text {th }}$ percentile in the 1990s, Meyer and Sullivan (2003) also find that expenditures exceeded income by $47 \%$ and $24 \%$ in the Consumer Expenditure (CE) and Panel Study of Income Dynamics (PSID) surveys, respectively. In subsequent papers, Meyer and Sullivan $(2004,2008,2012)$ find that low percentiles of consumption rose in the period following welfare reform and that deep consumption poverty has fallen sharply over time.

Additional papers in recent years have used the CE Survey to calculate decidedly low rates of consumption-based extreme poverty (spending less than $\$ 2$ or $\$ 4 /$ person/day) or deep poverty (spending less than half the official poverty line). Chandy and Smith (2014) find that only $0.07 \%$ of the U.S. population spent less than \$2/person/day in the fourth quarter of 2011. Hall and Rector (2018) examine all households interviewed in the CE survey since 1980 and similarly find that $0.08 \%$ of the U.S. population spent less than $\$ 4 /$ person/day. They also calculate an expenditurebased deep poverty rate of $0.5 \%$ in 2017 , which is considerably lower than the official income-based deep poverty rate of more than 6\% in 2017. Much like the results in Meyer and Sullivan (2012), Hall and Rector find that deep consumption poverty fell sharply from a rate of roughly $2 \%$ in the mid1980s, with this fall being especially precipitous for single parents after welfare reform.

\section{Why are Extreme Poverty Rates from Survey-Reported Cash Income So High?}

There are several major reasons why the literature has found such high rates of extreme poverty when relying on survey reports of pre-tax cash income. First, these calculations ignore inkind transfers and tax credits. The majority of means-tested transfer dollars are in-kind, and a broad range of authors has argued that non-medical in-kind benefits should be counted as income (see, for example, Ellwood and Summers, 1985; Citro and Michael, 1995; Blank, 2008). In particular, SNAP and WIC benefits can be plausibly treated as cash payments, since benefit amounts usually fall below the pre-receipt food expenditures of recipient families (Hoynes and Schanzenbach, 2009; BenShalom et al. 2012). The gross rents that are used to calculate housing assistance amounts have also been found to be close to market rents and thus similar to the valuation that private renters put on the units (Olsen 2018). Several studies have even argued that the per-dollar value of benefits from transfer programs may exceed cash earnings, as transfers play an important role in insuring earnings shocks (Blundell, Pistaferri, and Preston 2008; Blundell 2014; Deshpande 2016). 
Given that the nature of the safety net in the U.S. has changed dramatically, it is important to account for in-kind transfers and tax credits when comparing outcomes over time. While cash welfare (Aid to Families with Dependent Children or AFDC, which became TANF) payments fell by two-thirds between 1996 and 2011, SNAP payments more than doubled and EITC benefits increased by approximately half during the same time period, both transferring more new dollars than were cut from TANF (Meyer, Mok, and Sullivan 2015). Other in-kind transfers like public and subsidized housing followed a similar upward spending trajectory over time. ${ }^{10}$ Consequently, focusing on changes in poverty rates based solely on pre-tax cash income is anachronistic. These concerns, in large part, motivated the reports that led the U.S. Census Bureau to start calculating the Supplemental Poverty Measure (SPM) in 2011, which takes into account many of the non-cash programs and tax credits not included in the official poverty measure. To their credit, Shaefer and Edin (2013) find that SNAP, tax credits, and housing subsidies together cut the pre-tax cash extreme poverty rate for households with children by $63 \%$ in 2011. But researchers and policymakers continue to highlight estimates that exclude these - and other - important government programs.

Another reason for high extreme poverty rates in the literature is that studies almost universally rely on survey income with substantial errors even after editing, despite many studies demonstrating significant holes in the income data that arise from survey underreporting. For example, Meyer and Mittag (2015) find that 63\% of Public Assistance recipients in the CPS and $44 \%$ in the SIPP in New York do not report receipt, while 43\% of SNAP recipients in the CPS and $19 \%$ in the SIPP do not report receipt. Bee and Mitchell (2017) find that $46 \%$ of pension income recipients do not report receipt in the CPS.

While the CPS has often been found to suffer from more pronounced underreporting than the SIPP, the latter is not immune to errors. Meyer and Wu (2018) find that, among single parent families, the poverty reduction effects of SSI, OASDI, and Public Assistance from the SIPP are each less than $44 \%$ of what the administrative data indicate. ${ }^{11}$ For all families, the SIPP yields effects on near poverty of SNAP and Public Assistance that are two-thirds and one-half, respectively, what the administrative data generate (Meyer and $\mathrm{Wu}$ 2018). These holes in the SIPP income data have also grown over time. Since 2000, there has been a 7 percentage point increase in the share of dollars missed by the SIPP for TANF, unemployment insurance, and workers' compensation (Meyer, Mok,

\footnotetext{
${ }^{10}$ See https://www.cbpp.org/research/housing/national-and-state-housing-fact-sheets-data.

${ }^{11}$ Meyer and $\mathrm{Wu}(2018)$ take the administrative data to be truth, though the administrative data are likely incomplete. For example, administrative tax data may miss individuals who do not file tax returns or whose employers fail to file.
} 
and Sullivan 2015). The share of SIPP dollars that are imputed has also doubled since 1990, and errors in reporting amounts for SSI and OASDI rose sharply between the 1996 and 2008 SIPP panels (Gathright and Crabb 2014).

These errors in survey-reported income are likely most pronounced at the very bottom of the reported income distribution. Many studies have suspected or found errors in income reports at the tails of the distribution (Lillard, Smith, and Welch 1986; Blank and Schoeni 2003; Bollinger, Hirsch, Hokayem, and Ziliak 2018). Especially in the left tail, research has shown that reported expenditures are often a multiple of reported incomes. This pattern has been found not only in U.S. survey data (see Meyer and Sullivan 2004, 2008; Hall and Rector 2018), but in Canadian and British survey data as well. Brzozowski and Crossley (2011) use data from the Canadian Survey of Household Spending and the Family Expenditure Survey to show that total expenditures exceed disposable income by approximately a multiple of five in the bottom decile of the income distribution. Brewer, Etheridge, and O'Dea (2017) use data from the United Kingdom Living Costs and Food Survey and find that households in the bottom 1\% of the income distribution (who live on less than $£ 75 /$ week) report a median expenditure level of $£ 400 /$ week, equivalent to the population median! The authors find that median expenditures are actually decreasing in income for households living on less than $£ 110$ /week. They are best able to explain this puzzle by underreporting of income rather than over-reporting of expenditures or consumption smoothing over time.

\section{Data}

This section describes the detailed sources of survey and administrative data we use in this paper. The section also explains how we link these data and the advantages of using the combined data over survey or administrative sources alone.

\section{Survey Data}

Our survey data primarily come from the 2008 Survey of Income and Program Participation (SIPP). In Section VIII, we also describe results using the Current Population Survey Annual Social and Economic Supplement (CPS). Each panel of the SIPP lasts several years, and individuals and households are followed longitudinally within each panel. Specifically, each respondent is interviewed every four months as part of an interview "wave". In each wave, the SIPP collects information about the income and government transfers received during the four months since the 
last interview wave. Nearly all of these income sources are reported at the month level. Accompanying these income data is detailed information on demographics, assets and liabilities, material well-being, and health status (among other items). Many of these characteristics are available in the SIPP topical modules. These sets of questions on a specific subject differ across interview waves and are asked on top of the core questions.

To begin from a known starting point in the literature, we focus on Wave 9 of the 2008 SIPP Panel, whose reference months span January 2011 to July 2011. ${ }^{12}$ This sample includes the observations used by Shaefer and Edin(2013). We also link topical modules from Wave 9 and other waves that include questions on material hardships and housing quality (Wave 9), assets and liabilities (Waves 7 and 10), and disability status (Wave 6). The proximity of Wave 9 to Waves 6,7, and 10 presents another advantage of focusing on Wave 9 in our analysis. This proximity aids the comparability of the time periods and reduces sample attrition from wave to wave. An additional benefit of examining Wave 9 is that it spans a single reference year, unlike many other waves. This choice makes linkage to tax records, which are at the annual level, more convenient.

The SIPP sample is intended to be representative of the civilian non-institutional resident population of the United States, excluding individuals living in institutions and military barracks. We use households - rather than families, as official poverty estimates do - as our units of analysis for two main reasons. First, many of the questions in the SIPP (such as equity values for specific assets and material hardship) are asked at the household level. Second, individuals who are particularly destitute may rely on the additional resources of those outside their immediate families. If so, the household may be the more natural unit for analyzing the circumstances of the extreme poor. In practice, the distinction is not especially important as $92 \%$ of all households and $94 \%$ of reported extreme poor households have one family (see Appendix Table A.1).

\section{Administrative Data}

Our administrative records are derived from a number of sources, which we broadly classify into two categories: tax records from the Internal Revenue Service (IRS) and Social Security Administration (SSA), and program receipt records from various state and federal agencies. Table 2

\footnotetext{
12 The interview wave spans 7 calendar months because of the staggered nature of the interviews. Respondents are divided into four groups, each of which has a different starting month in the wave. For example, one set of respondents in Wave 9 has reference months spanning January-April 2011. The other three sets of respondents each have reference months spanning February-May 2011, March-June 2011, and April-July 2011.
} 
describes for each income component the source of the administrative data, the income unit, the disbursement frequency, and the number of states covered.

\section{Tax Records}

Earnings data covering wage and salary jobs and self-employment are available from the Detailed Earnings Record (DER) database of the SSA. The DER itself is derived from IRS W-2 Forms (for wage and salary jobs) and Schedule SE of IRS 1040 Forms (for self-employment). The DER includes wage and salary earnings that are below the 1040 filings requirement, though it misses other sources of earnings that we note later. We also have data on various forms of asset income from IRS 1040 Forms, including taxable dividends and taxable and tax-exempt interest. Data on retirement distributions come from IRS 1099-R Forms, which cover gross distributions from employer-sponsored plans (defined benefit and defined contribution plans) and IRA withdrawals. Finally, we calculate eligible EITC amounts based on filing status, earned income, and qualifying dependents in the prior year's IRS 1040 Forms.

As Table 2 indicates, the tax data contain universe records spanning the entire United States. These data are at the level of the tax unit, which consists of a single individual or married couple filing together with any eligible dependents. Note that the tax unit is conceptually distinct from a household, even if the two units are equivalent for most people. Furthermore, we convert annual data from the administrative tax records to monthly amounts by dividing the total amounts by twelve and distributing them evenly across all months in the calendar year.

\section{Program Participation Records}

Administrative records for Social Security (OASDI) come from the SSA's Payment History Update System (PHUS) file, with our preferred measure of total benefits including any amounts that are deducted for medical insurance premiums. Data on Supplemental Security Income (SSI) come from the SSA's Supplemental Security Record (SSR) file and include all federally-administered payments that are initially split into federal payments and federally-administered state payments. OASDI and SSI benefits are paid to individuals on a monthly basis. For housing assistance, our administrative data come from the Public and Indian Housing Information Center (PIC) and Tenant Rental Assistance Certification System (TRACS) files. These data cover almost all public and subsidized housing assistance programs under the jurisdiction of HUD. We calculate the benefit 
amount for a household as the difference between the gross rent and actual tenant payment. ${ }^{13}$ However, the records miss large housing programs such as those under the Department of Agriculture, which serve over a quarter million households (Scally and Lipsetz 2017), and those requiring landlords to charge below-market rents, which cover more than two million units (Scally et al. 2018). Supplemental Nutrition Assistance Program (SNAP) records come directly from various state agencies, and we have records for eleven states in 2011. Housing assistance and SNAP benefits are recorded and disbursed to households on a monthly basis.

\section{Linking Survey and Administrative Data}

We link the administrative data to the SIPP using Protected Identification Keys (PIKs) created by the U.S. Census Bureau's Person Identification Validation System (PVS) (Wagner and Layne 2014). Over $99 \%$ of most administrative records are associated with a PIK, and nearly $97 \%$ of hou seholds in Wave 9 of the SIPP contain at least one member associated with a PIK. To account for the likely small bias arising from non-random missing PIKs, we divide the household survey weights by the predicted probability that at least one member of the household has a PIK, conditional on observed characteristics in the survey (see Wooldridge 2007). This approach keeps the sampleas comprehensive as possible at the expense of understating the income from administrative sources for household members who cannot be linked. The appendix provides a full discussion of the inverse probability weighting adjustment. We have also conducted bounding exercises using the surveybased extreme poverty rates of unlinked households, which are sufficiently close to the rates for linked households that the loss of $3 \%$ of the sample has a trivial impact. We link all benefit dollars from an administrative SNAP or housing case to a survey household as long as there is a common individual between each unit. For the EITC and asset income, we link only to individuals in survey households who are primary and secondary filers in the tax data. ${ }^{14}$

\footnotetext{
${ }^{13}$ Because the administrative data do not include gross rent amounts for public housing units (which constitute less than a quarter of all households in the administrative data), we impute the market rent for these units based on the average rent by five-digit zip code, household size, and year. If rent is still missing, we impute by three-digit zip code, household size, and year - and subsequently by five-digit zip code and year and by three-digit zip code and year if needed. We consider a household to be receiving subsidized housing for the twelve months since the most recent certification date as long as the period is prior to any termination date.

${ }^{14}$ If an administrative case links to multiple survey households, we distribute benefit dollars from the administrative case proportionally to the number of individuals linked to each household.
} 


\section{Methods}

To begin, we define our baseline measure of extreme poverty (based on survey reports of cash income) and explain the decisions involved in constructing this measure. We then describe how we can improve on this reported measure using only the survey data. These adjustments involve incorporating non-medical in-kind transfers, undertaking conservative corrections for errors in reported earnings, and accounting for substantial assets. Next, we illustrate how bringing in the administrative data further improves the measurement of extreme poverty beyond what is possible in the survey. Lastly, we validate each of the survey-only adjustments by examining the administrative incomes and survey-reported material hardships, housing circumstances, and demographics of the groups removed from extreme poverty by the adjustments. Through confirming that those characterized as not extreme poor are well-off according to other indicators, the resulting measure reflects multiple dimensions of material well-being. As a check on our results, we examine the prevalence of those who are not in extreme poverty according to the survey but are reclassified as extreme poor after substituting in the administrative data. This group turns out to be miniscule.

\section{Defining Extreme Poverty and Sample Construction}

A number of different definitions of extreme poverty or "disconnectedness" have been used in the literature. As discussed in Section II, one of the most well-known standards considers a household to be in extreme poverty if the household's income is less than or equal to $\$ 2$ per-person, per-day. Various papers use slightly different cutoffs or differ in what is included in income and the period over which income is measured, though most report results for multiple definitions. ${ }^{15} \mathrm{We}$ start from pre-tax money income, which includes earnings, asset and retirement income, cash transfers, and other money income that a household may receive. ${ }^{16}$ This definition - which the Census Bureau's official poverty measure uses to calculate income - ignores in-kind transfers such as SNAP and tax credits like the EITC, though the SPM includes them. These sources of income have grown in importance over the last two decades. Subsequently, we show the degree to which a

\footnotetext{
${ }^{15}$ Deaton (2018) uses a cutoff of $\$ 4$ in income after taxes and in-kind transfers per-person, per-day. Blank and Kovak (2009), in their study use three alternative definitions of disconnected single mother families: those with 1) no earnings or welfare receipt over an entire year, 2) less than \$2000 in earnings and \$1000 in cash welfare, or 3) the income in (2) plus annual SSI income less than $\$ 1000$. United Nations (2018) relies on Deaton.

16 "Other money income" can include sources like child support, income assistance from charitable groups, and money from friends or relatives.
} 
measure of extreme poverty based on this cash income definition (hereafter referred to as "reported extreme poor") holds up after various corrections and adjustments.

In this paper, we consider a household to be in extreme poverty if its average monthly income over the reference months in a wave is less than \$2/person/day. ${ }^{17}$ Empirically, we observe considerable overlap between observations with reported cash income below \$2/person/day and who are "disconnected" based on various definitions from Blank and Kovak (2009), suggesting that our results likely generalize to analyses of disconnectedness. ${ }^{18}$ Furthermore, we define extreme poverty at the wave level, though the results are very similar at the month level. ${ }^{19}$ There are several reasons to analyze extreme poverty at the wave level. First, a wave provides a more comparable time period than a month to use when linking with annual tax records. Second, to keep our results comparable to measures in other surveys such as the CPS, we want to use a single retrospective interview rather than the multiple interviews needed to construct calendar quarters or years. ${ }^{20}$

While previous analyses have focused on households with children (see Shaefer and Edin 2013, 2017), we study all households and investigate how the prevalence of extreme poverty differs across five mutually exclusive and exhaustive household types: households headed by someoneaged 65 or older (elderly) and four non-elderly household types (single parent, multiple parents, single individual, and multiple adults without children). ${ }^{21}$ This disaggregation is informative given that eligibility for transfer programs is often dependent on household type (e.g., being elderly, having children).

\section{Corrections and Adjustments Using Survey and Administrative Data}

We now describe the corrections and adjustments made using survey and administrative data to improve upon the reported extreme poverty rate. Our preferred specification implements the

\footnotetext{
${ }^{17}$ In Section VIII, we also present results using a threshold of $\$ 4 /$ person/day.

${ }^{18}$ Suppose we define being "disconnected" as having less than $\$ 166.67$ in monthly earnings, $\$ 83.33$ in cash welfare, and $\$ 83.33$ in SSI income, which corresponds to one of the definitions in Blank and Kovak (2009) when the annual thresholds are converted to monthly values. Then, among single mother-headed households (the focus of the literature on disconnectedness), $86 \%$ with reported cash incomes below $\$ 2 /$ person/day are disconnected while $42 \%$ that are disconnected have reported cash incomes below \$2/person/day. See Appendix Table A.21 for estimates corresponding to alternative definitions of disconnectedness.

${ }^{19}$ See Appendix Table A.6 for the month-level results and Table 3a for the wave-level results.

${ }^{20}$ Starting with the 2014 Panel, the SIPP underwent a redesign where - among other changes - interviews are now conducted annually rather than every four months. However, the accuracy of the redesigned SIPP remains in question (National Academies of Sciences 2018).

${ }^{21}$ As we note in the appendix, there are some very rare cases where we classify individuals under 18 as adults - e.g., a 17 -year-old single mother living on her own with her children.
} 
survey-only adjustments before bringing in the administrative data, since this anchors our results to a literature that has relied only on survey data and allows many of our results to be replicated using publicly available data. We also present results using alternative orders to our adjustments, such as bringing in the administrative data first.

\section{Survey Data}

Here, we describe the corrections and adjustments made using only survey data to improve upon the reported extreme poverty rate. We first incorporate the following in-kind transfers: SNAP, WIC, and housing assistance. Following the methodology in Shaefer and Edin (2013) to account for in-kind transfers, we reclassify a household as not extreme poor if 1) its total cash income plus survey-reported values of SNAP and WIC benefits exceeds $\$ 2 /$ person/day or 2) it receives any form of housing assistance. ${ }^{22}$

Among those still in extreme poverty after incorporating in-kind transfers, we calculate lower-bound earnings based on survey reports of hours worked for pay, under the assumption that workers earn at least the federal minimum wage (\$7.25/hour). We then remove households from extreme poverty if the earnings resulting from this correction for missing dollars exceed \$2/person/day. ${ }^{23}$ We first identify the households removed by lower-bound earnings using only reported wage and salary hours. Subsequently, we identify households removed by lower-bound earnings for reported hours worked in self-employment jobs as well. One might worry that this algorithm applies less well to off-the-books and/or self-employment jobs where the federal minimum wage does not apply. As a robustness check, we apply half the federal minimum wage to hours worked for pay, which leaves our final result unchanged. The vast majority of individuals removed by these corrections report a full set of employment characteristics but zero earnings, and they work in occupations typically paid above the minimum wage. This finding suggests that the zero earnings,

\footnotetext{
${ }^{22}$ The assumption behind including housing assistance in this way is that the monetary value of public or subsidized housing is worth at least $\$ 2 /$ day per person. For this not to be true, the assistance amount for a two-person household would have to be less than $\$ 120 /$ month, which seems implausible. As a robustness check, we impute average housing assistance amounts from the administrative data based on county, household size, and year (and county and year if still missing) and designate a household as being lifted out of extreme poverty if its total cash income + survey-reported SNAP and WIC benefits + imputed housing assistance amount exceeds \$2/person/day. The results are identical.

${ }^{23}$ Alternatively, we could add all other (non-earnings) survey-reported income to these lower-bound earnings and compare the resulting amount to $\$ 2 /$ person/day. We choose to use our more conservative correction because the extreme poverty threshold is so low and, as is, very few hours are required to remove a household from extreme poverty. For example, a single person needs to work only 9 hours in a month to earn above $\$ 2 /$ day. In practice, whether or not we choose to add other survey-reported income to minimum wage earnings changes the results by only a few hundredths of a percentage point.
} 
rather than the positive hours worked (most of which are not imputed), are anomalous and thus recorded incorrectly. ${ }^{24}$ The appendix provides a thorough discussion of how we calculate these lower-bound earnings and the occupations associated with households removed by these corrections.

Our last survey-only adjustment accounts for households holding substantial assets. Among those still left in extreme poverty after incorporating in-kind transfers and lower-bound earnings, we consider a household to not be in extreme poverty if its reported real estate equity exceeds $\$ 25,000$, liquid assets exceed $\$ 5,000$, or total net worth exceeds $\$ 50,000 .{ }^{25}$ We include the restriction that households must have positive total assets to be reclassified by this adjustment. We obtain asset amounts from the topical modules to Waves 7 and 10 of the SIPP. While we acknowledge that assets are not part of cash or in-kind income, it seems inappropriate to consider households with sizeable assets that could be drawn upon to be in extreme poverty. We later show that the preponderance of these households would be removed by the administrative data corrections, but we feel it is important to show what can be done with the survey data alone. ${ }^{26}$ It should be noted that the SPM accounts for assets in its thresholds, and the Haig-Simons definition of income-along with authoritative sources on poverty measurement like Ruggles (1990) and Citro and Michael (1995) explicitly recognizes that not accounting for assets is problematic. Asset tests are also part of the eligibility requirements for most means-tested programs, and Ruggles (1990) states that a primary reason for not accounting for assets in poverty measurement is simply that most surveys do not ask about assets (p. 149).

\footnotetext{
${ }^{24}$ Census Bureau employees indicated that editing choices that should probably be changed are responsible for at leasta substantial share of these cases. Among all individuals aged 15 or above with zero earnings and positive wage/salary hours worked in Wave $9,69.7 \%$ report an hourly wage, $95.4 \%$ of all hourly wage reports are above the federal minimum wage, and $99.6 \%$ of all hourly wage reports are above half the federal minimum wage (per the public use data). This implies that our minimum wage assumption is sensible and - if anything - an underestimate. We further verify that the vast majority of households removed by these corrections have incomes above \$2/person/day from the administrative records, and they resemble the average household in the U.S. on various measures of reported well-being.

${ }^{25}$ Real estate equity includes home equity and equity in any other real estate, including mobile homes. Liquid assets include checking accounts, savings accounts, money market accounts, bonds, securities, mutual funds, debt or margin accounts, certificates of deposits, and stocks. Total net worth equals total assets (liquid assets, retirement accounts, real estate equity, vehicle equity, business equity, and the value of other financial investments - i.e., "equity in other assets") minus secured and unsecured debt.

${ }^{26}$ In the end, the adjustment for substantial assets increases our final extreme poverty rate by only 0.13 percentage points. This is because $0.46 \%$ of households are removed from extreme poverty by the assets adjustment (Table $3 a$ ), and $28.2 \%$ of these households have incomes below $\$ 2 /$ person/day in the administrative data (Figure 3). Multiplying these numbers results in $0.13 \%$ of all households that are removed from extreme poverty by the assets adjustment (our final survey-only adjustment before bringing in the administrative data) but not the administrative data.
} 


\section{Administrative Data}

Given the underreporting of many types of income such as government transfers and private pensions, we bring in administrative data to further refine the extreme poverty rate. Among those still in extreme poverty after all survey-only adjustments, we consider households to not be extreme poor if their incomes exceed $\$ 2 /$ person/day after replacing survey reports with administrative measures for various income sources. The administrative data can help account for false negatives among recipients of transfer programs and gross errors in reported amounts, among other survey errors. We first replace survey reports of earnings, interest and dividends, and retirement distributions with values from administrative tax records. ${ }^{27} \mathrm{We}$ then add EITC amounts calculated from tax records. ${ }^{28}$ We hereafter refer to these income sources collectively as "tax data income".

Next, we replace survey reports of OASDI, SSI, housing assistance, and SNAP with values from administrative program records. ${ }^{29}$ We hereafter refer to these income sources collectively as "transfer income". We are able to directly incorporate OASDI, SSI, and housing assistance for all states, while we use administrative SNAP records for 11 states (covering 29\% of the population) to estimate the effect of the administrative SNAP data for all states. Specifically, we calculate our final estimate of the extreme poverty rate by multiplying the rate after accounting for the survey-only adjustments, the administrative tax data, and the administrative non-SNAP transfer data (calculated over all 50 states) by the fraction of such households in the 11 states remaining in extreme poverty after bringing in the administrative SNAP data. By taking this approach, we need only assume that these 11 states are representative of the entire country in the marginal impact of the administrative SNAP data, which is weaker than assuming they are representative in the level of extreme poverty. However, Appendix Table A.8 shows these 11 states are indeed similar to the rest of the country on

\footnotetext{
${ }^{27}$ Since survey reports may cover earnings from off-the-books and non-standard jobs that are not reported to the IRS (see Abraham, Haltiwanger, Sandusky, and Spletzer 2013, 2017), it may instead be justified to take the maximum of survey and administrative reports of earnings. By simply replacing survey reports of earnings with administrative tax earnings, we run the risk of trivially overstating the extreme poverty rate. In practice, it does not matter for this analysis whether or not we take the maximum of survey and administrative values. Since the survey values must lie below $\$ 2 /$ person/day at the stage when we bring in the administrative data, there is effectively no difference between taking just 1) the administrative earnings values and 2) the maximum of the administrative earnings values and minuscule survey values (the vast majority of which are zero).

${ }^{28}$ We use eligible EITC amounts calculated based on the administrative tax data rather than actual amounts. While this will overstate the true amount of the EITC disbursed, the upward bias associated with eligible EITC amounts is likely substantially smaller than the downward bias in survey-based imputations of EITC amounts. We find that the actual EITC dollars disbursed (from publicly available IRS totals) are $90 \%$ of the total eligible dollars that we calculate. In contrast, aggregate EITC dollars imputed in the CPS understate disbursements by approximately $30 \%$ (Meyer 2017).

${ }^{29}$ For SSI, we only have administrative data on federally-administered benefits, even though states can separately administer benefits themselves. Thus, our preferred measure of total SSI ben efit amounts sums administrative values for federally-administered SSI and survey values for state-administered SSI.
} 
a number of demographic and economic characteristics. ${ }^{30}$ As we show in the next section, whether or not we include the administrative SNAP data at all makes very little difference for our final results.

\section{Validating the Survey-Only Adjustments}

We recognize that our adjustments using only the survey data are imperfect. For example, some earnings, such as those from self-employment or off-the-books, are not subject to minimum wage legislation. Moreover, the survey reports of hours worked and assets may themselves be misreported. Consequently, we thoroughly validate the appropriateness of each survey-only adjustment using information from the administrative data and detailed measures of well-being from the SIPP topical modules. Poverty definitions should be examined to see how they accord with other indicators of disadvantage, but - in practice - measures are typically chosen for other reasons without such validation. ${ }^{31}$ First, for each subgroup of the reported extreme poor removed by a survey-only adjustment, we directly calculate the share of households with incomes above $\$ 2 /$ person/day after replacing survey values with the available administrative data values for various income sources. To investigate the extent of gross errors, we also calculate the share of households in each subgroup with incomes above half the poverty line (the deep poverty cutoff), the poverty line, and twice the poverty line based on the administrative data. ${ }^{32}$

As a second check on the validity of the survey-only adjustments, we compare the groups removed from extreme poverty to the official poor and all households based on survey-reported measures of hardship and housing quality. ${ }^{33}$ Conveniently, these measures of material well-being are collected from the same interview wave (Wave 9) as the income measures. For material hardships, we examine survey answers (yes/no) to nine separate questions on a range of hardships, including not being able to pay all essential expenses, rent, mortgage, or an energy bill, having energy or telephone service disconnected, being evicted, inability to see a doctor or dentist, and a lack of food. We also examine ownership of the following eight appliances: microwaves,

\footnotetext{
${ }^{30}$ Households in the SNAP states have extreme, deep, and official poverty rates (measured based on cash income) that are insignificantly different from the rates in the full sample. Fewer households in the SNAP states receive OASDI and SSI, and more receive SNAP, Public Assistance, and housing assistance than those in the full sample, though only the differences for SSI, SNAP, and housing assistance are statistically significant at the $5 \%$ level.

${ }^{31}$ Exceptions include Mayer and Jencks (1989) and Meyer and Sullivan $(2003,2011,2012)$.

${ }^{32}$ For a single non-elderly individual, the average monthly poverty line in Wave 9 corresponds to $\$ 32.15 /$ person/day.

${ }^{33}$ For the analyses on survey-reported well-being and demographics, we use the full survey sample and original survey weights (as opposed to the PIKed sample and adjusted survey weights).
} 
dishwashers, air conditioners, color televisions, computers, in-unit washers, in-unit dryers, and cell phones. $^{34}$ We further investigate whether a household faces any of seven housing quality issues, including problems with pests, a leaking roof, broken windows, exposed wires, plumbing problems, and cracks or holes in the walls, ceiling, or floors. An advantage of examining material hardships and housing problems is that these measures may be more indicative of deprivation, while an advantage of examining appliances is that they can be easily and objectively measured. The appendix provides a more detailed description of the specific hardship and material well-being variables used. Finally, we assess additional demographic and economic characteristics reported in the SIPP - such as student status, educational attainment, health insurance coverage, and asset ownership - to obtain an even better picture of each group removed from extreme poverty.

\section{Main Results}

\section{Extreme Poverty After Adjustments}

Table 3 a displays the share of households that are left in extreme poverty after successively incorporating each adjustment. ${ }^{35}$ The first column starts with survey-reported cash incomeand finds that $2.97 \%$ of all households report having less than $\$ 2 /$ person/day of cash income. ${ }^{36}$ However, nearly a third of these households are reclassified as not extreme poor by survey-reported in-kind transfers, with the extreme poverty rate for households falling to $2.04 \%$. Nearly $95 \%$ of the impact of survey-reported in-kind transfers is attributable to survey-reported SNAP (see Appendix Table A.5). Correcting for errors in reported earnings based only on reported wage and salary hours worked for pay decreases the extreme poverty rate for households to $1.83 \%$. Further accounting for reported self-employment hours worked decreases the extreme poverty rate for households to $1.30 \%$. All told, correcting for errors in reported earnings removes an additional 36\% of households from extreme poverty. Accounting for substantial assets again reduces the extreme poverty rate by overa third, leaving us with $0.84 \%$ of households remaining in extreme poverty.

\footnotetext{
${ }^{34}$ We exclude certain appliances (refrigerators, freezers, stoves, and regular telephones) that we think households are likely to own regardless of their material circumstances, precisely in an effort to capture those appliances that are most strongly indicative of well-being.

${ }^{35}$ Standard errors are calculated using replicate weights corresponding to Wave 9 of the 2008 SIPP.

${ }^{36}$ The reported extreme poverty rate of $2.97 \%$ calculated using the PIKed subsample and adjusted survey weights is nearly identical to the reported extreme poverty rate of $3 \%$ calculated using the entire sample and original survey weights. See Appendix Tables A.2, A.3, and A.4 for versions of Tables 3a, 3b, and 6 using the public-use SIPP data.
} 
While adjustments using only the survey data eliminate most of extreme poverty, the administrative tax and program data provide additional information. Applying the administrative earnings data alone removes an additional $50 \%$ of those remaining in extreme poverty and cuts the extreme poverty rate to $0.42 \%$. Incorporating the administrative data on asset and retirement income decreases the extreme poverty rate to $0.35 \%$, and adding the EITC further reduces the rate to $0.31 \%$. Bringing in administrative data on OASDI and SSI lowers the extreme poverty rate to $0.27 \%$, which decreases insignificantly to $0.24 \%$ after bringing in the administrative housing assistance and SNAP data. ${ }^{37}$ Of the additional households removed from extreme poverty by the administrative data, $67 \%$ have incomes above half the poverty line and 55\% have incomes above the poverty line. ${ }^{38}$ This finding suggests that there are still non-trivial gross errors in the extreme poverty rate after the survey-only adjustments. Together, the adjustments reduce extreme poverty by $92 \%$ from a reported rate of $2.97 \%$, with more than three-quarters of the total reduction due to corrections and adjustments using the survey data alone.

We observe a similar pattern for individuals, with in-kind transfers cutting the extreme poverty rate the most and each of the other adjustments also removing a sizable portion of individuals out of extreme poverty. When looking at only reported cash income, we find that $2.60 \%$ of individuals live on less than $\$ 2 /$ day. After accounting in the survey for in-kind transfers, reported hours worked, and substantial assets, the extreme poverty rate falls by more than three-quarters to $0.57 \%$. Bringing in the administrative tax and transfer data further reduces the extreme poverty rate to $0.11 \%$. The extreme poverty rates for individuals are lower than those for households because extreme poor households tend to have fewer members.

\section{Extreme Poverty by Household Type}

We now analyze how extreme poverty differs by household type. Shaefer and Edin focus on two of the five household types (those with children), while the "disconnected families" literature focuses on single parent households. We first consider elderly households, who tend to have a

\footnotetext{
${ }^{37}$ Standard errors at the final step (bringing in administrative SNAP values) are calculated using the delta method.

${ }^{38}$ These numbers are calculated from Figure 3. Among the remaining extreme poor (after survey-only adjustments), $71 \%$ and $47.9 \%$ have incomes above the extreme and deep poverty lines, respectively. Because those with incomes above the deep poverty line are a subset of those with incomes above the extreme poverty line, we can calculate that $67 \%(49.1 \%$ divided by $72.3 \%$ ) of those above the extreme poverty line are also above the deep poverty line. A similar logic follows for the poverty line.
} 
significantly lower extreme poverty rate than other household types. ${ }^{39}$ The elderly begin with a reported extreme poverty rate of $0.47 \%$, less than one-sixth the rate for all households (Figure $3 \mathrm{a}$, Column 2). After incorporating each of the survey-only adjustments, $0.11 \%$ of elderly households remain in extreme poverty. Bringing in the administrative tax and non-SNAP transfer data removes nearly $90 \%$ of the remaining households from extreme poverty. Perhaps not surprisingly for these elderly households, the role of the administrative data is driven entirely by improved measures for three income sources: retirement distributions, OASDI, and SSI (Table 4, Column 2). The final estimate of the elderly extreme poverty rate is $0.01 \%$ (insignificantly different from zero) prior to bringing in administrative SNAP records, and it becomes zero after incorporating SNAP.

We next consider single parent households (Table 3a, Column 3), whose reported extreme poverty rate of $8.99 \%$ is more than three times and statistically significantly above the rate for all households. ${ }^{40}$ However, about two-thirds of single parent households are reclassified as not extreme poor by survey-reported in-kind transfers. The extreme poverty rate for single parent households then declines to $1.97 \%$ and $1.35 \%$ after correcting for underreported earnings and accounting for substantial assets in the survey, respectively. After bringing in the administrative tax data, the extreme poverty rate for single parents falls to $0.1 \%$, which is insignificantly different from zero. Most of this reduction is due to administrative earnings and the EITC (calculated from prior year earnings). After including the administrative SNAP data, no single parent households remain in extreme poverty. Among single parent households in the remaining extreme poor after the surveyonly corrections, $75 \%$ have positive earnings from the tax records and $69 \%$ receive at least one transfer - usually SNAP or the EITC - per the administrative data (Table 4, Column 3).

Unlike single parent households, multiple parent households start with a reported extreme poverty rate of $2.04 \%$ that is significantly below that of all households (Table 3a, Column 4 ). Inkind transfers noticeably decrease their extreme poverty rate by $43 \%$, and the subsequent adjustments for reported hours worked and assets bring down their extreme poverty rate to $0.27 \%$. Like single parents, multiple parent households have an estimated extreme poverty rate of zero after incorporating the administrative data. This impact of the administrative data is driven again by the

\footnotetext{
${ }^{39}$ The only exception to this rule is that the elderly do not have a significantly lower extreme poverty rate than multiple parent households after the self-employment correction.

${ }^{40}$ See Appendix Table A.7 for the results of two-sample t-tests comparing the extreme poverty rate for every household type to all other household types, before and after every adjustment.
} 
role of earnings and transfers, with more than $70 \%$ of the remaining extreme poor after survey-only adjustments having positive earnings and $79 \%$ receiving a transfer (Table 4 , Column 4 ).

Households containing a single non-elderly individual have a reported extreme poverty rate of $6.85 \%$, which - while lower than that of single parent households - is still 2.3 times and statistically significantly higher than that of all households (Table 3a, Column 5). Single individuals are not nearly as impacted by the adjustments and therefore have the highest extreme poverty rate of any hou sehold type after every adjustment. We are left with $2.86 \%$ of single individual households in extreme poverty after the survey-only adjustments, which is almost as high as the overall reported extreme poverty rate. Bringing in the administrative data also has a smaller effect on single individuals, removing just $61 \%$ of single individuals remaining in extreme poverty after the surveyonly adjustments. This relatively smaller reduction is due to several factors. First, single individuals appear to be particularly disconnected from the safety net, with only $31 \%$ of the remaining extreme poor after the survey-only corrections receiving at least one transfer. ${ }^{41}$ Second, the majority of these remaining extreme poor single individuals do not have earnings (Table 4, Column 5). We are therefore left with a final extreme poverty rate of $1.12 \%$ for non-aged single individuals.

Multiple childless adult households have a reported extreme poverty rate (1.90\%) not far from that of multiple parent households (Table 3a, Column 6). The survey adjustments for in-kind transfers, reported hours worked, and substantial assets together decrease their extreme poverty rate by more than three-quarters to $0.44 \%$. After adding in administrative tax and transfer data, the extreme poverty rate for multiple adults becomes $0.07 \%$. Among the remaining extreme poor after survey-only adjustments, multiple adults have far more earnings than single individuals (Table 4, Column 6) and have a high in-kind transfer receipt rate. Consequently, $85 \%$ of multiple adult households among the remaining extreme poor after survey-only adjustments are removed by the administrative data (compared to only $61 \%$ of single individuals).

In summary, the combined survey and administrative data indicate that extreme poverty is extremely rare for the elderly, families with children, and multiple adult households, as we cannot reject for each household type the null hypothesis that its final extreme poverty rate is equal to zero at the $1 \%$ significance level (though we can reject the null at the $5 \%$ level for multiple parents and multiple adults). Single individuals, of whom 252,000 population-weighted individuals are extreme

\footnotetext{
${ }^{41}$ Tests of differences across household types are often indecisive when restricted to the smaller set of states with SNAP data. Focusing on transfers besides SNAP and those remaining in extreme poverty after the survey corrections, single individuals have a significantly lower receipt rate than all other household types except multiple adult households.
} 
poor after all adjustments, constitute the only household type whose final extreme poverty rate is statistically significantly different from zero at the $1 \%$ significance level.

\section{Distribution of Household Types}

Not only do the errors in the income data exaggerate the level of extreme poverty, but they also lead to a distorted image of the type of households likely to be at the very bottom. Among the reported extreme poor, single individuals make up the largest share at nearly 44\% (Figure 1a). Households with children form the next largest shares, with single and multiple parent households together making up about $36 \%$ of the reported cash income extreme poor (about 18\% each). Multiple adult households also make up about $17 \%$ of the reported extreme poor, while elderly households contribute only a little over $3 \%$. However, as we add each adjustment, single individual households constitute an increasingly larger share. After the survey-only adjustments, they constitute $65 \%$ of the remaining extreme poor households. Once we incorporate the administrative tax and non-SNAP transfer data, single individuals make up more than $83 \%$ of all extreme poor households, with this share rising to nearly $92 \%$ after bringing in the administrative SNAP data.

While single individuals constitute a disproportionate share of the households in extreme poverty, we may also want to consider the composition of extreme poverty in terms of the share of individuals living in extreme poor households (Figure 1b). When analyzing extreme poverty at the individual level, we find that only about $19 \%$ of the reported extreme poor are single individuals, while 59\% are members of households with children (about 23\% single parent and 36\% multiple parent). Multiple adults make up another $19 \%$, and the elderly contribute $2.7 \%$. Nonetheless, we see with each adjustment the same, albeit less dramatic, pattern that we saw with households, as single individuals make up an ever-larger share of extreme poor individuals. Specifically, single individuals make up $37 \%$ of the remaining extreme poor individuals after the survey-only adjustments, and they make up almost $81 \%$ of extreme poor individuals after all adjustments.

\section{Corrections and Adjustments Using Only the Administrative Data}

Figure 2 illustrates the results of an alternative order to the adjustments that incorporates the administrative data first. We can see that $55.1 \%$ of households among the reported extreme poor have incomes above $\$ 2 /$ person/day from the administrative earnings records alone. Bringing in the other administrative sources of money income shows that a full $73 \%$ of reported extreme poor 
households are misclassified due simply to errors in cash reports of earnings, asset income, retirement distributions, OASDI, and SSI and the omission of the EITC. When we add in administrative sources of in-kind transfers (housing assistance and SNAP), 83.1\% have incomes above the extreme poverty threshold. This implies that the administrative data alone can decrease the extreme poverty rate from a reported cash base of $2.97 \%$ to $0.50 \%$. The adjustments using only the survey data then take the extreme poverty rate down by an additional 0.26 percentage points to $0.24 \%$. Thus, when incorporated first, the administrative data can account for $90 \%$ of the change in extreme poverty due to all adjustments.

Furthermore, nearly half of all reported extreme poor households have incomes above the poverty line and over a fifth have incomes above twice the poverty line. This finding makes it clear that there is a vast amount of error associated with classifying households as extreme poor based solely on their survey-reported cash income. We can also show from Figure 2 that $79 \%$ of all misclassified households are initially categorized as extreme poor due to direct errors in cash reports of tax data income, OASDI, and SSI and the omission of the EITC. ${ }^{42}$ This share must be a lower bound for those misclassified due to all errors in cash income, because the DER (our source of administrative data) misses the income of low-paid household workers and undocumented immigrants, as well as other income such as tips not reported to an employer. The DER will also miss off-the-books income. Consequently, in-kind transfers play a secondary role relative to errors in cash reports in explaining the high reported extreme poverty rate.

\section{Validation of Survey-Only Adjustments}

We now describe the results obtained from validating each of the survey-only adjustments through comparisons to administrative income data and survey reports of material well-being and selected demographics. Throughout this subsection, the "remaining extreme poor" subgroup refers to households that are left in extreme poverty after the survey-only adjustments.

\footnotetext{
${ }^{42}$ To calculate this share, note that $92 \%$ of all reported cash extreme poor households are misclassified (since the adjustments decrease the rate from a base of $2.97 \%$ to $0.24 \%$ ). We also know from Figure 4 that $73 \%$ of reported extreme poor households are misclassified due to errors in cash reports of tax data income, OASDI, and SSI and the omission of the EITC. Because these households are a subset of all misclassified households, we divide $73 \%$ by $92 \%$ to obtain the share of all misclassified households initially among the reported cash extreme poor due to errors or omissions in cash reports.
} 


\section{Administrative Income Data}

We first examine the share of households in each extreme poor subgroup with income above \$2/person/day (and other thresholds) according to the administrative data (see Figure 3). While the administrative data are our most accurate source for many income components, they still have important gaps. We lack administrative data on TANF, unemployment insurance, workers' compensation, VA benefits, the child tax credit, and other income sources. In two of the key domains (earnings and housing benefits) where we do have administrative data, the sources are incomplete. The gaps in the DER are mentioned above, while the PIC/TRACS data miss housing assistance benefits paid out by non-HUD programs. Yet, we are able to confirm the vast majority of our corrections and adjustments with these incomplete data.

First, for the households reclassified as not extreme poor by survey-reported in-kind transfers, over $99 \%$ have incomes above $\$ 2 /$ person/day according to the administrative tax and transfer data. As expected, the administrative transfer data play a relatively large role for this subgroup, with nearly a third of its households removed from extreme poverty by administrative transfers after accounting for income from the administrative tax records. The tiny percentage of households not raised above $\$ 2 /$ person/day by the administrative data may be due to incomplete administrative data, incomplete linkage, or survey false positives. The correction for reported wage and salary hours is similarly robust, with $93 \%$ of the hou seholds removed by this correction having incomes from the administrative data confirmed above the extreme poverty threshold. Convincingly, $89 \%$ of these households are removed from extreme poverty by the administrative earnings alone. This subgroup also appears to have substantial gross errors, with $65 \%$ of households having incomes above the poverty line and $45 \%$ having incomes above twice the poverty line.

There is slightly less confirmation of the corrections for reported self-employment hours and substantial assets. Among the households removed due to reported self-employment hours, 70\% have incomes above $\$ 2 /$ person/day based on administrative earnings alone and $78 \%$ have incomes above the threshold using all administrative tax and transfer data. While these shares are still large, they are smaller than those for the groups reclassified by in-kind transfers and wage and salary hours. This discrepancy could be due in part to the underreporting of self-employment earnings on tax returns (Internal Revenue Service 2016). The error is unlikely to result from the assumption of

minimum wage earnings being too high of a lower bound for self-employment earnings, given the relatively high-earning self-employment occupations and industries reported for this group 
(Appendix Tables A.15 and A.17) and the similarity of the results using half the minimum wage (Table 7). Among the households removed from extreme poverty due to substantial assets, $67 \%$ are not extreme poor based on the administrative tax data and $72 \%$ are not extreme poor based on the administrative tax and transfer records. However, note once again the high fraction of gross errors in this subgroup, with $47 \%$ of households having incomes above the poverty line and $27 \%$ above twice the poverty line.

We therefore find strong evidence that these survey-only adjustments are by and large confirmed by the administrative data. The adjustments for in-kind transfers and reported wage and salary hours are particularly robust, with nearly all reclassified households having incomes above $\$ 2 /$ person/day in the administrative data. The adjustments for reported self-employment hours and substantial assets are less strongly validated by the administrative data, but it is important to remember that our administrative data do not completely cover all income sources and do not cover assets at all.

\section{Survey-Reported Material Well-Being}

To assess the material well-being of the potentially misclassified reported extreme poor households, we make use of detailed questions available in the SIPP topical modules. These questions on material hardships, housing problems, and appliances owned allow us to perform yet another test of the validity of our survey-only adjustments. Figure 4 displays the mean number of material hardships experienced by households among the reported extreme poor and the groups removed by each adjustment. The dotted line shows the mean for all official poor households, while the dashed line shows the mean for all households. Figure 5 shows the share of households with at least one hardship, while Figure 6 shows housing problems and Figure 7 appliance ownership. ${ }^{43}$

Looking first at the number of hardships, which ranges from 0 to 9 , a clear pattern appears. The reported extreme poor experience 1.22 hardships on average. This count is slightly below but insignificantly different from the number of material hardships, 1.29 , experienced by official poor households. ${ }^{44}$ Assuming that the truly extreme poor should experience more hardships than the

\footnotetext{
${ }^{43}$ In Appendix Table A.11, we also report for all extreme poor and subgroups the percent with each of these hardships, appliances, or problems, as well as the percent of households with at least one hardship, appliance, or problem (and for material hardships, the percent of households with five or more material hardships). See Appendix Figures A.1-A.4 for a breakdown of these patterns by household type.

${ }^{44}$ See Appendix Table A.9 for the results of two-sample t-tests comparing the well-being measures for every extreme poor subgroup with those of official poor and all households.
} 
official poor, this finding suggests that there could be substantial classification error in the reported extreme poor. Indeed, we see that sharp differences between subgroups of the reported extreme poor add up to the overall result. Most of the subgroups do not experience hardships at a level commensurate with extreme poverty, although one of the subgroups does.

Focusing first on the subgroup that appears especially disadvantaged, households that are removed from extreme poverty by in-kind transfers experience on average of 1.98 hardships, 53\% more hardships than official poor households (with this gap being statistically significant). Recipients of in-kind transfers are clearly among the worst-off non-institutionalized Americans, which importantly suggests that these transfer programs are well-targeted. On the other hand, the groups removed from extreme poverty by wage and salary hours, self-employment hours, and substantial assets experience about the same number of hardships as a typical household in the U.S. Specifically, those removed by wage and salary hours have 0.53 hardships, $13 \%$ fewer than the average of 0.61 over all households, while those removed by self-employment hours and substantial assets have 0.67 and 0.65 hardships, only $10 \%$ and $7 \%$ more, respectively, than the average household. For none of these subgroups is the difference in mean hardships from all households statistically significant. Thus, rather than being extreme poor or even poor, these households appear to be close to average or better. The remaining extreme poor after the survey-only corrections average 1.21 hardships, which is insignificantly different from the average number of hardships experienced by the official poor. This last result suggests that some substantial errors still remain, which is not surprising since the remaining group includes those households that are not in extreme poverty when incorporating the administrative data. Similar patterns emerge when we analyze the share of households reporting least one hardship (Figure 5) or having five or more hardships (Appendix Table A.11).

Examining housing quality issues and appliance ownership reveals patterns that are similar but often less dramatic than those for material hardships. The reported extreme poor have on average 0.36 housing quality problems and 5.98 appliances, which is insignificantly different from the 0.40 housing problems and 5.91 appliances of the official poor. These two comparisons again suggest that there are problems with the designation of extreme poverty in the raw reported data. Those households reclassified as not extreme poor due to in-kind transfers have a very high rate of housing problems, 0.43 on average (though this is insignificantly different from the official poor), 
and they own 5.49 appliances, significantly fewer than the official poor. Again, these gaps demonstrate the good targeting of in-kind transfers.

On the other hand, the households removed from extreme poverty due to reported hours worked or substantial assets have a mean number of housing problems closer to the overall average. Households removed by wage and salary hours worked and by substantial assets have on average 0.28 and 0.30 problems respectively, which is in between (and insignificantly different from) the average level for all households and the official poor. Those removed by self-employment hours have on average 0.23 problems, significantly lower than those of the official poor and insignificantly different from those of all households. The households removed by self-employment hours also own 6.90 appliances on average, a high level compared to the other subgroups, ${ }^{45}$ and the households removed by wage and salary hours and substantial assets have 6.64 and 6.73 appliances, respectively, or $4 \%$ and $2 \%$ fewer than all households. For none of these subgroups is the difference from all hou seholds in mean appliances statistically significant. Finally, the remaining extreme poor again are insignificantly different from the official poor on the mean number of housing problems, but they own statistically significantly fewer appliances (almost 10\% less) than the official poor.

In Appendix Table A.12, we also test whether the differences in material well-being between the groups removed from extreme poverty by the survey-only adjustments remain after controlling for demographic covariates. To do so, we regress an indicator of well-being (mean number of hardships, appliances, or housing problems) on a dummy for whether a household is poor based on pre-tax cash income, separate dummies for whether a household is removed from extreme poverty by a given adjustment, and covariates for the age of the household head and the number of children and adults in the household. Even after the inclusion of covariates, we find that the households removed from extreme poverty by in-kind transfers continue to be significantly worse off than poor households while those removed by the earnings and asset adjustments have hardships insignificantly different from the average non-poor household.

In sum, while some of the indicators of well-being may be imperfect on their own, we observe the same pattern across every measure - that the hou seholds removed from extreme poverty by in-kind transfers are materially worse off than the official poor, while the households removed

\footnotetext{
${ }^{45}$ This number is statistically significantly higher at the $1 \%$ level than that of households removed by in-kind transfers and the remaining extreme poor after survey corrections, but it is not significantly different than that of households removed by wage/salary hours or assets.
} 
from extreme poverty by the earnings and assets adjustments have a level of material well-being similar to the average over U.S. households.

\section{Survey-Reported Demographics}

To provide a clearer picture of the households among the reported extreme poor and each of its subgroups, we report their demographic characteristics in Table 5. First, note that $12.0 \%$ of the reported extreme poor are full-time students, significantly higher than the $7.2 \%$ of official poor households and $2.6 \%$ of all households. We disaggregate this number across subgroups and find that the remaining extreme poor have a high rate of student status, with full-time students heading $18.1 \%$ of its households. Student status could proxy for access to other sources of financial support for which we do not account, such as financial aid (cash or in-kind), unreported assistance from parents, and student loans. Indeed, more than half of student-headed households among the remaining extreme poor report receiving educational assistance not included in cash income. ${ }^{46}$

The patterns in educational attainment across each of the extreme poor subgroups also reflect the patterns observed for material well-being. The heads of reported extreme poor households have an average of 12.9 years of education, which is roughly midway between the average of 12.2 for the official poor and the overall average of 13.6. Households that are considered to not be extreme poor due to in-kind transfers have an average of 12.0 years of education, the lowest of any group and significantly lower than the levels for the official poor and all households. The households removed by self-employment hours and substantial assets have even more education than the average for all households, but the differences are statistically insignificant. Those removed by wage and salary hours have 13.0 years of education and the remaining extreme poor have 12.8 years of education, both roughly midway between the levels for the official poor and all households.

We observe similar patterns in reported health insurance coverage. The subgroup reclassified as not extreme poor by in-kind transfers has the highest rate of Medicaid coverage at 49.9\%, 1.5 times the rate of official poor households. ${ }^{47}$ Conversely, those households removed by reported hours or substantial assets have very high rates of private insurance coverage, with near or above $50 \%$ of these households covered. While these private coverage rates are not as high as that of all

\footnotetext{
${ }^{46}$ Our survey-reported measure of cash income includes GI bill education benefits, but none of our survey or administrative income sources includes other measures of educational assistance. See p. 3-7 of the SIPP Users' Guide: https://www2.census.gov/programs-surveys/sipp/guidance/SIPP_2008_USERS_Guide_Chapter3.pdf

${ }^{47}$ Note that our time period is before the Affordable Care Act broadened Medicaid eligibility.
} 
households at $69.73 \%$, they are significantly higher than the $25.7 \%$ rate of official poor households. The hou seholds remaining in extreme poverty after the survey-only corrections have the lowest rate of health insurance coverage, but over a quarter of their heads still have some form of health insurance coverage (mostly private insurance).

Table 5 also examines ownership rates of several assets, including homes, vehicles, and liquid assets. The households reclassified as not extreme poor by in-kind transfers and those remaining in extreme poverty have very low asset ownership rates. In contrast, those households removed by wage and salary earnings have similar asset ownership rates to the official poor, while the households removed by self-employment earnings own assets at rates similar to the average for all households. Among the households considered to not be extreme poor after accounting for substantial assets, more than $63 \%$ have total net worth exceeding $\$ 100,000$ and $31 \%$ have total net worth over $\$ 250,000 .{ }^{48}$ Appendix Table A.13 provides an expanded version of Table 5 and looks at a broader set of demographic and economic characteristics for these subgroups.

\section{Comparison to Current Population Survey Results}

While we focus on the SIPP in this paper, we are also interested in examining whether our results generalize to the CPS ASEC (hereafter referred to as the CPS). In addition to serving as the official source of poverty and income statistics in the United States, the CPS is one of the most widely used surveys. Because the CPS collects a sparser set of information on income and wellbeing than the SIPP, we can only incompletely replicate our analysis.

\section{Data \& Methods}

We use the 2012 CPS, which interviewed 74,383 households in March 2012 about their annual incomes in the previous calendar year. Thus, the reference period for the CPS includes the seven months that comprise Wave 9 of the 2008 SIPP. Our sample consists of households that have at least one member with a PIK and no members that are whole imputes, with survey weights adjusted to account for missing PIKs and the presence of whole imputes (see the appendix for more information). We employ a set of adjustments similar to those used for the SIPP but proceed in a slightly different order, allowing us to better compare the estimates of extreme poverty in the two surveys. We start with households living on less than \$2/person/day over the course of 2011

\footnotetext{
${ }^{48}$ There are even a handful of households in this subgroup with net worth in the millions (i.e., extremely gross errors).
} 
according to their survey-reported cash income. We first correct for underreported earnings based on reported hours worked. We multiply a household's annual hours worked (as reported in the survey) by the federal minimum wage and remove households from extreme poverty if these lowerbound earnings are above the extreme poverty threshold. This is done separately for wage and salary hours and for total hours worked (which include self-employment hours).

Next, we incorporate in-kind transfers by reclassifying a household as not extreme poor if 1 ) its total cash income plus survey-reported SNAP benefits exceeds $\$ 2 /$ person/day or 2) it receives housing subsidies. ${ }^{49}$ We do not include WIC payments because WIC amounts are not reported in the CPS. We subsequently account for substantial assets in the CPS in a slightly different manner than in the SIPP. The CPS does not contain as detailed information as the SIPP on the specific amounts of various types of assets, but it does ask about home value and whether or not a household has a mortgage. We therefore remove a hou sehold from extreme poverty if it has no mortgage and a home value greater than $\$ 25,000$, or if a household has a mortgage and a home value greater than $\$ 100,000$. Finally, we remove a household from extreme poverty if its annual income from cash and in-kind transfers from the administrative data exceeds $\$ 2 /$ person/day. The reference period of the CPS actually aligns better than the SIPP with the administrative tax records because both are for the calendar year. We follow these alternative methods in this Section for both the SIPP and the CPS to allow a close comparison.

\section{Results}

Table 6 reports the extreme poverty rate after each adjustment in the CPS and compares it to the rate after the same aligned adjustment in the SIPP. The reported extreme poverty rate in the CPS of $2.08 \%$ (Column 1 ) is statistically significantly less than the corresponding rate of $2.97 \%$ in the SIPP (Column 2). Correcting for underreported wage and salary earnings reduces the gap in the estimates between surveys, with the extreme poverty rate declining by 0.29 percentage points to $2.68 \%$ in the SIPP and falling slightly by 0.03 percentage points to $2.05 \%$ in the CPS. Correcting for underreported self-employment earnings remarkably closes this gap, with the extreme poverty rate dropping to $2.07 \%$ in the SIPP and remaining almost unchanged at $2.03 \%$ in the CPS. We are unable to reject the null hypothesis that these rates are equal to each other (see Column 3).

\footnotetext{
${ }^{49} \mathrm{We}$ assume that if a household reports receiving housing assistance, then it receives housing assistance for all 12 months of 2011. This follows the assumption that the U.S. Census Bureau makes when calculating the Supplemental Poverty Measure (Johnson, Renwick, and Short 2011).
} 
Including SNAP and housing assistance cuts the extreme poverty rate by approximately a third in both surveys, yielding insignificantly different extreme poverty rates of $1.35 \%$ and $1.30 \%$ in the CPS and SIPP, respectively. Note that SNAP and housing assistance are by far the most important in-kind transfers, since including WIC (as our original SIPP adjustment for in-kind transfers does) has virtually no impact on the extreme poverty rate (Column 4). Accounting for substantial assets further reduces the extreme poverty rate to $0.96 \%$ in the SIPP and $0.80 \%$ in the CPS. ${ }^{50}$ Bringing in administrative earnings cuts the extreme poverty rate by about half in both surveys, and bringing in the additional tax data on asset income, retirement income, and the EITC decreases the extreme poverty rate to $0.35 \%$ in the SIPP and $0.34 \%$ in the CPS. After incorporating the administrative transfer data, we obtain a final extreme poverty rate among households of $0.18 \%$ in the CPS and $0.29 \%$ in the SIPP, which are statistically significantly different at the $5 \%$ significance level. Much of the final gap between the two surveys is due to the administrative data for OASDI and SSI playing a larger role in reducing the extreme poverty rate in the CPS. However, the difference in the final extreme poverty rate between the CPS and the original adjustments in the SIPP is statistically insignificant (Column 5). We also calculate an extreme poverty rate of $0.13 \%$ for individuals in the CPS, compared to the rate of $0.11 \%$ rate we reported earlier for the SIPP.

Consequently, the results for the two surveys are far more alike than they initially seem. The sizeable errors that we find in the left tail of the SIPP income distribution appear with almost the same frequency in the CPS. The primary difference is that households almost never report positive hours worked and extremely low earnings in the CPS, while such a pattern is relatively common among the reported cash extreme poor in the SIPP. ${ }^{51}$ Our final estimates of the extreme poverty rate in Column 7 are also consistent with the idea that poverty over the course of an entire year (CPS) should be less frequent than poverty over the course of four months (SIPP). Finally, the larger impact of the administrative transfer data on the CPS estimate is in line with work showing greater underreporting of transfer programs in the CPS relative to the SIPP (Meyer, Mok, and Sullivan 2015).

\footnotetext{
${ }^{50}$ Due to the more limited asset information available in the CPS, the adjustment for substantial assets that we utilize here is narrower than what we utilize for the main SIPP results. Specifically, the extreme poverty rate in the SIPP after accounting for assets is $0.96 \%$ using this more limited adjustment, compared to $0.84 \%$ using the original adjustment (which also accounts for liquid and total assets).

${ }^{51}$ In the CPS, all households that report 0 earnings also report 0 hours worked across all members. In the SIPP, $7.94 \%$ of all households that report 0 earnings report positive average monthly hours worked for pay. Also in the SIPP, $72 \%$ of households lifted out of extreme poverty by wage and salary hours reported 0 earnings, as did $88 \%$ of households lifted out of extreme poverty by self-employment hours.
} 


\section{Robustness Checks and Caveats}

\section{Robustness Checks}

We conduct a series of robustness checks to examine the sensitivity of our results to a wide set of alternative specifications. Table 7 presents the results of several key checks. First, we apply half the federal minimum wage (rather than the full minimum wage) to reported wage/salary and self-employment hours worked. This modification increases the extreme poverty rate by a mere 0.01 percentage points after the survey corrections for underreported earnings, and leaves the final extreme poverty rate after all adjustments unchanged (Column 1). We also calculate estimates excluding survey-reported and administrative values of housing assistance, given concerns about the lack of fungibility of housing assistance. The final extreme poverty rate after all adjustments, but prior to bringing in the administrative SNAP records, is once again 0.01 percentage points above the comparable rate accounting for housing assistance (Column 2). As expected, SNAP is responsible for most of the impact of in-kind transfers.

We also examine whether our extreme poverty results extend to a higher income cutoff specifically \$4/person/day (see Allen 2017, Deaton 2018). Column 3 of Table 7 shows that they do. As expected, the extreme poverty rates are higher when measured using a higher income threshold. The reported rate of $3.68 \%$ using $\$ 4 /$ person/day is $24 \%$ higher than the rate using $\$ 2 /$ person/day, and the final rate of $0.34 \%$ after incorporating all adjustments using $\$ 4 /$ person/day is $42 \%$ higher than the rate using $\$ 2 /$ person/day (but still very low). The similar patterns using $\$ 4 /$ person/day are consistent with a relatively large number of household reports of zero income, many of which are likely to be gross errors. The survey-only adjustments also cut the reported extreme poverty rate by $73 \%$ when using the $\$ 4 /$ person/day threshold, which is comparable to the $72 \%$ cut by the surveyonly adjustments when using the $\$ 2 /$ person/day threshold.

Next, we examine whether our methodology misses households that should be extreme poor but have survey-reported incomes greater than $\$ 2 /$ person/day due to imputation or over-reporting. ${ }^{52}$ We find that a minuscule number of households have incomes greater than $\$ 2 /$ person/day in the survey but fall under $\$ 2 /$ person/day after setting imputed earnings equal to zero and applying the administrative data - specifically, taking the maximum of survey and administrative values for earnings and housing assistance (since the administrative values for these sources are incomplete as

\footnotetext{
${ }^{52} \mathrm{We}$ consider an amount to be imputed if it is statistically imputed (i.e., hot or cold deck). We do not consider logically imputed amounts to be imputed, because they are based on previous wave information that is likely to be of good quality.
} 
noted earlier), replacing survey with administrative values for interest and dividends, retirement income, OASDI, SSI, and SNAP, and adding EITC amounts calculated from the administrative tax records. We also analyze how our results change after basing our survey correction for underreported earnings only on non-imputed hours worked and ignoring retirement accounts in the survey adjustment for assets. Once again, the results barely budge following each modification.

We also calculate estimates of extreme poverty at the level of the fourth reference month, which is regarded as having the most accurate survey reports (Moore 2008) and follows the reference period in Shaefer and Edin (2013). Appendix Table A.6 displays estimates after each survey-only adjustment using the fourth reference month and finds that they are only slightly higher than our wave-level estimates. For example, using the fourth reference month, the reported extreme poverty rate of $3.82 \%$ and the extreme poverty rate of $1.09 \%$ after accounting for substantial assets are each $25-30 \%$ higher than the comparable wave-level rates. The similarity of the estimates across the month and wave reference periods reflects the tendency of survey responses to be strongly correlated when taken within the same interview (Moore 2008).

It is not clear what is the appropriate time interval for measuring income poverty. Most of the literature on income and well-being has argued for looking over a full year, given transitory fluctuations in income that may not be reflected in consumption or other outcomes. There is also a long literature that emphasizes the persistence of poverty or argues for looking at income over multiple years (see Duncan and Rogers 1991 or Solon 1992, for example). As well as looking at a shorter time interval than a four month wave, we considered examining SIPP estimates over a calendar year. While there are advantages to a longer period, we do not do so in the SIPP because of attrition across interview waves. Furthermore, responses would be taken across three or four interviews (rather than one), making it less comparable to surveys like the American Community Survey (ACS) and CPS ASEC that cover a reference year in a single interview. However, the results in the CPS strongly suggest that the patterns and levels of annual estimates mirror those of wavelevel estimates in the SIPP.

We also examine more closely the households removed from extreme poverty due to reported hours worked. Among the top 10 occupations of workers in households removed by wage and salary and self-employment hours, most are not exempt from the federal minimum wage and, in fact, would seem to have average earnings that are generally far above minimum wage (see Appendix Tables 
A.14 and A.15) ${ }^{53}$ For example, almost $9 \%$ of workers in households removed from extreme poverty by wage and salary hours are computer scientists or engineers (compared to less than $2 \%$ of all wage and salary workers). Additionally, while $1.41 \%$ of workers in this subgroup are waiters and waitresses (an occupation that could conceivably earn less than minimum wage), a higher rate $(1.82 \%)$ of all wage and salary workers are waiters and waitresses. Additionally, the three most common occupations for workers in households removed from extreme poverty by self-employment hours are various kinds of managers (14\% of such workers, as compared to $11.55 \%$ of all selfemployed workers). To get a sense of the extent to which these subgroups are likely to have errorridden earnings reports, Appendix Table A.18 also displays the share of households in these subgroups with zero, single-digit, or double-digit reported average monthly earnings. We find that $72 \%$ of households removed by wage and salary hours report zero earnings and that $91 \%$ report zero, single-digit, or double-digit earnings. Of the households removed by self-employment hours, $88 \%$ report zero earnings and $94 \%$ report zero, single-digit, or double-digit earnings.

Finally, we check to see that imputed values in the survey only have a minor effect on our estimates. For example, 59\% of households reclassified by survey-reported in-kind transfers have SNAP amounts imputed, but only 3\% have receipt imputed (see Appendix Table A.19). Encouragingly, $99 \%$ of the households reclassified by survey-reported in-kind transfers have incomes above $\$ 2 /$ person/day based on the administrative data. We also find that $9 \%$ of households removed by wage and salary hours have imputed values for overall hours worked (see Appendix Table A.20). Once again, $93 \%$ of the households removed by wage and salary hours have incomes above the extreme poverty threshold based on the administrative data.

\section{Caveats}

In this subsection, we discuss some weaknesses in our data and their likely effect on our results. We first discuss reasons why we may have understated the extent of extreme poverty and then reasons why we may have overstated it. First, we rely on annual administrative tax data that we allocate evenly across the four months of the SIPP wave. If the months of the year with low other income are also those with low taxable income, then we will understate extreme poverty. The results from the CPS suggest that this bias is small, since the CPS yields strikingly similar results to those in the SIPP even though CPS income is annual and does not suffer from this potential misalignment.

\footnotetext{
${ }^{53}$ Appendix Tables A.16 and A.17 show the top 10 industries of these workers.
} 
Furthermore, we may be less worried about this possibility as it could only occur when a household is only transitorily extreme poor. Given that most of those who we remove from extreme poverty via the administrative data have income over twelve months above the poverty line, to be extreme poor for four months would require these households to have income one and a half times the extreme poverty line over the remaining months of the year. It is worth emphasizing that the potential misalignment between annual and wave-level data does not apply to the administrative program data, which are all at the month level.

Second, and probably most importantly, the SIPP and CPS survey frames cover only resident households, meaning they miss homeless individuals (among other institutionalized populations). Given that there were 636,000 homeless individuals in 2011 (based on HUD estimates) and that the homeless are among the most destitute members of our communities, our final estimate of the extreme poverty rate may be an understatement for the entire population. ${ }^{54}$ While the extreme poverty estimates in the literature discussed in Section II also rely on surveys that do not include the homeless, a broader view of extreme poverty would include them. Moreover, if homeless individuals are more likely than the non-homeless to be single and childless, then incorporating the homeless might further amplify the already large share of single childless extreme poor individuals.

There are also reasons why our data may overstate extreme poverty. First, we are unable to include administrative data for a number of income sources, such as Temporary Assistance for Needy Families, General Assistance, the Child Tax Credit, unemployment insurance, workers' compensation, non-DER earnings, non-HUD housing assistance, and veterans' benefits. ${ }^{55}$ Figure 9 shows that we miss $\$ 216$ billion from the four largest transfer programs or tax credits not in our administrative data, with $\$ 107$ billion attributable to unemployment insurance alone. The total expenditures for these "excluded" programs are similar to the total expenditures for the non-OASDI programs for which we have administrative data. ${ }^{56} \mathrm{We}$ likely also miss income from sources like off-the-books employment and money from relatives (Jencks 1997). ${ }^{57}$ Incorporating administrative sources for these other income components may lead to further reductions in the extreme poverty

\footnotetext{
${ }^{54}$ See https://www.hudexchange.info/resources/documents/2011AHAR_FinalReport.pdf.

${ }^{55}$ While we have access to administrative TANF data and have used them in previous work (see Meyer and Wu 2018), we only have these data for 30 states and are hesitant to base our extreme poverty estimates on the seven states for which we have both administrative SNAP and TANF data.

${ }^{56}$ According to Meyer, Mok, and Sullivan (2015), the expenditures in 2011 are $\$ 48.9$ billion for SSI, $\$ 72.8$ billion for SNAP, and $\$ 62.9$ billion for the EITC. Based on Table 8.7 in the OMB's Historical Tables, the expenditures for housing assistance in calendar year 2011 (calculated from amounts for fiscal years 2011 and 2012) are \$46.8 billion.

${ }^{57}$ There are good reasons to believe that the non-tax earnings in the survey are themselves underreported (Hurst, $\mathrm{Li}$, and Pugsley 2014; Hokayem, Bollinger, and Ziliak 2015).
} 
rate. In fact, we find that more than $20 \%$ of the remaining extreme poor households contain veterans, which may be due in part to our administrative data excluding information on veterans' benefits.

Second, we are unable to access asset information for a substantial share of our households since the asset information is from either a few months before or after our Wave 9 reference period. Because of survey attrition and slight changes in household composition across waves, not all households that appear in Wave 9 match to topical modules from the other waves (especially later waves). ${ }^{58}$ Therefore, any households that do not link to the topical modules for Waves 7 or 10 are not removed from extreme poverty by substantial assets. In fact, one-sixth of the un-weighted households left in extreme poverty after accounting for substantial assets cannot be linked to the Wave 7 or 10 topical modules. This missing data problem leads to an understatement of the asset adjustment and therefore an overstatement of the final extreme poverty rate. We should also note that incomplete linking of individuals means we cannot bring in administrative data for all survey respondents, likely understating their income. Finally, the year we examine was near the peak of the most severe recession in 70 years, so incomes were atypically low. Overall, we expect that the incompleteness of our data - especially the linked administrative data - leads to an overstatement of households in extreme poverty, but the omission of the homeless (who are not in households) is an important gap in our information.

\section{Conclusions}

Through closely examining the SIPP and augmenting the survey data with administrative tax and transfer data, we find that $92 \%$ of the households categorized as extreme poor based on surveyreported cash income are misclassified. Our methodology yields a similar finding in the CPS, where $91 \%$ of the households categorized as extreme poor based on survey-reported cash income are misclassified. Consequently, we estimate that $0.24 \%$ of households in the United States lived on \$2/person/day or less over a four-month period in 2011 (SIPP) and $0.18 \%$ of households lived on $\$ 2 /$ person/day or less over the course of the entire 2011 reference year (CPS). The corresponding share of individuals in the SIPP is $0.11 \%$. Many of the households included in survey-reported

\footnotetext{
${ }^{58}$ From the publicly available SIPP data, $92.55 \%$ of the households (weighted) we use in Wave 9 link to the Wave 6 topical module. $97.88 \%$ of households we use in Wave 9 link to either Wave 10 or Wave 7: we link $90.83 \%$ to Wave 10 and $7.05 \%$ to Wave 7 (we only link households to Wave 7 if we could not link them to Wave 10).
} 
extreme poverty appear to be better off than the average American household based on numerous indicators of material well-being. These results are consistent with the literature showing that survey data at the very bottom of the income distribution are especially error-ridden. The results also reflect the very low rates of extreme and deep consumption poverty that various studies have found. Importantly, we may yet overstate the true rate of extreme poverty, because our administrative data miss a number of important income sources for which surveys underreport or miss altogether.

This paper further demonstrates that the face of extreme poverty is quite different from what the literature has previously emphasized. Among the 285,000 households left in extreme poverty, 90\% are made up of single individuals. Households with multiple childless individuals make up the other $10 \%$ of the extreme poor. Strikingly, after implementing all adjustments, no SIPP-interviewed households with children have incomes below $\$ 2 /$ person/day. This result lies in stark contrast to the focus in academic and policy circles on the plight of extreme poor households with children. This result also indicates that extreme poverty among such households, given its low current level, cannot have risen in an economically meaningful way due to welfare reform. It is worth re-emphasizing that these dramatic results hold even in the absence of administrative data for TANF, which is targeted towards single-parent households and is heavily underreported in surveys.

Our results also indicate that means-tested transfers - especially in-kind benefits - are welltargeted to the needy, as the households reclassified as not extreme poor by in-kind transfers appear to be considerably worse off than those in official poverty. We therefore provide an explanation for the imperfect ability of the U.S. Census Bureau's Supplemental Poverty Measure to select those with low material well-being (see Meyer and Sullivan 2012): it likely reclassifies as non-poor those receiving in-kind transfers, who are very needy, and leaves as poor those who are misclassified because of substantial assets or unreported income.

This paper leaves room for a number of extensions. First, one could examine post-tax measures of extreme poverty. While this paper does calculate the EITC from administrative tax records, it does not account for all tax credits (like the Child Tax Credit) and tax liabilities. Second, one could incorporate more complete administrative data as they become available (e.g., on veterans' benefits, unemployment insurance, and workers' compensation). Doing so would also help us understand how many of the single individuals we categorize as being in extreme poverty are misclassified because of missing administrative data. The wide variety of information in the SIPP may also allow greater understanding of the significant number of extreme poor single individuals. 
More generally, we lay out a novel methodology for how income data can be better used to measure poverty. We show that our adjustments using exclusively the survey data go a long way in addressing survey errors, accounting for $78 \%$ of the change in extreme poverty due to the combination of survey-only and administrative-based adjustments. Although this paper focuses on extreme poverty, we can apply a similar methodology to address survey errors at higher income cutoffs such as the deep and official poverty thresholds. By combining the accuracy of the administrative data with the detail of the SIPP data, one may also be able to better understand the barriers to success faced by households that are truly poor. 


\section{References}

Abraham, Katherine G., John Haltiwanger, Kristin Sandusky, and James R. Spletzer. 2013. Exploring Differences in Employment between Household and Establishment Data. Journal of Labor Economics, 31(2): S129-S172. . 2017. Measuring the Gig Economy. Working Paper. Washington, D.C.: U.S. Census Bureau.

Allen, Robert C. 2017. Absolute Poverty: When Necessity Displaces Desire. American Economic Review, 107(12): 3690-3721.

Bee, Adam and Joshua Mitchell. 2017. Do Older Americans Have More Income Than We Think? SESHD Working Paper 2017-39. Washington, D.C.: U.S. Census Bureau.

Ben-Shalom, Yonatan, Robert Moffitt, and John K. Scholz. 2012. An Assessment of the Effectiveness of Anti-Poverty Programs in the United States. In P.N. Jefferson (Ed.), The Oxford Handbook of the Economics of Poverty. Oxford: Oxford University Press.

Blank, Rebecca M. 2008. Presidential Address: How to Improve Poverty Measurement in the United States. Journal of Policy Analysis and Management, 27(2): 233-254.

Blank, Rebecca and Brian Kovak. 2009. The Growing Problem of Disconnected Single Mothers. In C. J. Heinrich and J. K. Scholz (Eds.) Making the Work-Based Safety Net Work Better. New York: Russell Sage Press.

Blank, Rebecca M. and Robert F. Schoeni. 2003. Changes in the Distribution of Children's Family Income over the 1990's. American Economic Review, 93(2): 304-308.

Blundell, Richard. 2014. Income Dynamics and Life-Cycle Inequality: Mechanisms and Controversies. The Economic Journal, 124 (May): 289-318.

Blundell, Richard, Luigi Pistaferri, and Ian Preston. 2008. Consumption Inequality and Partial Insurance. American Economic Review, 98(5): 1887-1921.

Bollinger, Christopher R., Barry T. Hirsch, Charles M. Hokayem, and James P. Ziliak. 2018. Trouble in the Tails? What We Know about Earnings Nonresponse Thirty Years after Lillard, Smith, and Welch. Journal of Political Economy (forthcoming).

Brady, David and Zachary Parolin. 2018. Increasing Deep and Extreme Poverty in the U.S., 1993-2015. Working Paper.

Brewer, Mike, Ben Etheridge, and Cormac O'Dea. 2017. Why are Households that Report the Lowest Incomes so Well-Off? The Economic Journal, 127 (October): F24-F49. 
Brzozowski, Matthew and Thomas F. Crossley. 2011. Viewpoint: Measuring the Well-Being of the Poor with Income or Consumption: A Canadian Perspective. Canadian Journal of Economics, 44(1): 88-106.

Bullard, James. 2013. President's Message: CPI vs. PCE Inflation: Choosing a Standard Measure. Regional Economist (Federal Reserve Bank of St. Louis).

Chandy, Laurence and Cory Smith. 2014. How Poor Are America's Poorest? U.S. \$2 A Day

Poverty In A Global Context. Washington, D.C.: Brookings Institute.

Citro, Constance F. and Robert T. Michael, (Eds.). 1995. Measuring Poverty: A New Approach. Washington, D.C.: National Academy Press.

Congressional Budget Office. 2012. The Distribution of Hous ehold Income and Federal Taxes, 2008 and 2009. Washington, D.C.: Congressional Budget Office.

Deaton, Angus. "The U.S. Can No Longer Hide From Its Deep Poverty Problem.” New York Times. 24 Jan 2018.

Deshpande, Manasi. 2016. Does Welfare Inhibit Success? The Long-Term Effects of Removing Low-Income Youth from the Disability Rolls. American Economic Review, 106(11): $3300-3330$.

Duncan, Greg J. and Willard Rodgers. 1991. Has Children's Poverty Become More Persistent? American Sociological Review, 56(4): 538-550.

Edin, Kathryn J. and H. Luke Shaefer. 2015. \$2.00 A Day: Living on Almost Nothing in America. Boston: Houghton Mifflin Harcourt.

Ellwood, David T. and Lawrence H. Summers. 1985. Measuring Income: What Kind Should be In? Conference on the Measurement of Noncash Benefits, U.S. Bureau of the Census.

Fox, Liana and Lewis Warren. 2018. Material Well-Being and Poverty: New Evidence Across Poverty Measures. APPAM Presentation Slides. Washington, D.C.: U.S. Census Bureau. Gathright, Graton and Tyler A. Crabb. 2014. Reporting of SSA Program Participation in SIPP. Working Paper. Washington, D.C.: U.S. Census Bureau.

Hall, Jamie B. and Robert Rector. 2018. Examining Extreme and Deep Poverty in the United States. Backgrounder No. 3285. Washington, D.C.: The Heritage Foundation.

Hokayem, Charles, Christopher Bollinger, and James P. Ziliak. The Role of CPS Nonresponse in the Measurement of Poverty. Journal of the American Statistical Association, 110(511): 935-945. 
Hoynes, Hilary W. and Diane Whitmore Schanzenbach. 2009. Consumption Responses to InKind Transfers: Evidence from the Introduction of the Food Stamp Program. American Economic Journal: Applied Economics, 1(4): 109-39.

Hurst, Erik, Geng Li, and Benjamin Pugsley. 2014. Are Household Surveys Like Tax Forms?

Evidence from Income Underreporting of the Self-Employed. Review of Economics and Statistics, 96(1): 19-33.

Internal Revenue Service. 2016. Tax Gap Estimates for Tax Years 2008-2010.

Jencks, Christopher. 1997. Introduction to Making Ends Meet, by Kathryn Edin and Laura Lein. New York: Russell Sage Foundation.

Johnson, Paul D., Trudi J. Renwick, and Kathleen Short. 2011. Estimating the Value of Federal Housing Assistance for the Supplemental Poverty Measure. SEHSD Working Paper 2010-13. Washington, D.C.: U.S. Census Bureau.

Lillard, Lee, James P. Smith, and Finis Welch. 1986. What Do We Really Know about Wages? The Importance of Nonreporting and Census Imputation. Journal of Political Economy, 94(3): 489-506.

Loprest, Pamela J. 2011. Disconnected Families and TANF. Temporary Assistance for Needy Families Program—Research Synthesis Brief Series. Washington, D.C.: The Urban Institute.

Loprest, Pamela and Austin Nichols. 2011. Dynamics of Being Disconnected from Work and TANF. Washington, D.C.: The Urban Institute.

Mayer, Susan E. and Christopher Jencks. 1989. Poverty and the Distribution of Material Hardship. Journal of Human Resources, 24(1): 88-114.

Medalia, Carla, Bruce D. Meyer, Amy O’Hara, and Derek Wu. 2019. Linking Survey and Administrative Data to Measure Income, Inequality, and Mobility. International Journal of Population Data Science 4:1:04.

Meyer, Bruce D. 2017. The Earned Income Tax Credit. In Robert Doar (Ed.), A Safety Net That Works: Improving Federal Programs for Low-Income Americans, pp. 1-18. Washington, D.C.: American Enterprise Institute.

Meyer, Bruce D. and Nikolas Mittag. Forthcoming. Using Linked Survey and Administrative Data to Better Measure Income: Implications for Poverty, Program Effectiveness and Holes in the Safety Net. American Economic Journal: Applied Economics. 
Meyer, Bruce D., Wallace K.C. Mok, and James X. Sullivan. 2009. The Under-Reporting of Transfers in Household Surveys: Its Nature and Consequences. NBER Working Paper No. 15181.

Meyer, Bruce D., Wallace K.C. Mok, and James X. Sullivan. 2015. Household Surveys in Crisis. Journal of Economic Perspectives, 29(4), 199-226.

Meyer, Bruce D. and James X. Sullivan. 2003. Measuring the Well-Being of the Poor Using Income and Consumption. Journal of Human Resources, 38:S, 1180-1220. . 2004. The Effects of Welfare and Tax Reform: The Material Well-Being of Single Mothers in the 1980s and 1990s. Journal of Public Economics, 88: 1387-1420. .2008. Changes in the Consumption, Income, and Well-Being of Single Mother Headed Families. American Economic Review, 98(5): 2221-2241. . 2011. Viewpoint: Further Results on Measuring the Well-Being of the Poor using Income and Consumption. Canadian Journal of Economics, 44(1): 52-87. . 2012. Identifying the Disadvantaged: Official Poverty, Consumption Poverty, and the New Supplemental Poverty Measure. Journal of Economic Perspectives, 26(3): 111-136.

Meyer, Bruce D. and Derek Wu. 2018. The Poverty Reduction of Social Security and MeansTested Transfers. Industrial and Labor Relations Review, 71(5): 1106-1153.

Mittag, Nikolas. 2019. Correcting for Misreporting of Government Benefits. American Economic Journal: Economic Policy, 11(2).

Moore, Jeffrey C. 2008. Seam Bias in the 2004 SIPP Panel: Much Improved, but Much Bias Still Remains. Survey Methodology 2008-3 Report. Washington, D.C.: U.S. Census Bureau. National Academies of Sciences, Engineering, and Medicine. 2018. The 2014 Redesign of the Survey of Income and Program Participation: An Assessment. Washington, D.C.: The National Academies Press. https://doi.org/10.17226/24864.

Olsen, Edgar O. 2018. Reported and Actual Housing Assistance Based on CPS and AHS Variables. Unpublished Note, January 30.

Parolin, Zachary and David Brady. Forthcoming. Extreme Child Poverty and the Role of Social Policy in the United States. Journal of Poverty \& Social Justice.

Ruggles, Patricia. 1990. Drawing the Line: Alternative Poverty Measures and their Implications for Public Policy. The Urban Institute Press, Washington D.C. 
Scally, Corianne P., Amanda Gold, Carl Hedman, Matt Gerken, and Nicole Dubois. 2018. The Low-Income Housing Tax Credit. Washington, D.C.: Urban Institute.

Scally, Corianne P. and David Lipsetz. 2017. New Public Data Available on USDA Rural Housing Service’s Single-Family and Multifamily Programs. Cityscape, 19(1): 295-304.

Shaefer, H. Luke, and Kathryn J. Edin. 2013. Rising extreme poverty in the United States and the response of federal means-tested transfer programs. Social Service Review, 87(2): 250268.

. 2017. Welfare Reform and the Families it Left Behind. Pathways, Fall 2017: 22-27. Stanford Center on Poverty and Inequality.

Shantz, Kathryn and Liana E. Fox. 2018. Precision in Measurement: Using State-Level Supplemental Nutrition Assistance Program and Temporary Assistance for Needy Families Administrative Records and the Transfer Income Model (TRIM3) to Evaluate Poverty Measurement. Washington, D.C.: U.S. Census Bureau.

Short, Kathleen S. 2005. Material and Financial Hardship and Income-Based Poverty Measures in the USA. Journal of Social Policy, 34(1): 21-38.

Solon, Gary. 1992. Intergenerational Income Mobility in the United States. American Economic Review, 82(3): 393-408.

Turner, Lesley J., Sheldon Danziger, and Kristin S. Seefeldt. 2006. Failing the Transition from Welfare to Work: Women Chronically Disconnected from Employment and Cash Welfare. Social Science Quarterly, 87(2): 227-249.

United Nations. 2018. Report of the Special Rapporteur on Extreme Poverty and Human Rights on His Mission to the United States of America.

U.S. Census Bureau. 2005. Alternative Poverty Estimates in the United States: 2003. P60 -227 Report. Washington, D.C.: U.S. Census Bureau.

U.S. Census Bureau. 2015a. Income and Poverty in the United States: 2014. P60-252 Report. Washington, D.C.: U.S. Census Bureau.

U.S. Census Bureau. 2015b. The Supplemental Poverty Measure: 2014. P60-254 Report. Washington, D.C.: U.S. Census Bureau.

Wagner, Deborah and Mary Layne. 2014. The Person Identification Validation System (PVS): Applying the Center for Administrative Records Research \& Applications' (CARRA) 
Record Linkage Software. CARRA Working Paper 2014-01. Washington, D.C.: U.S. Census Bureau.

Winship, Scott. 2016. Poverty After Welfare Reform. Washington, D.C.: Manhattan Institute.

Wooldridge, Jeffrey M. 2007. Inverse Probability Weighted Estimation for General Missing Data Problems. Journal of Econometrics, 141: 1281-1301. 


\section{Tables and Figures}

Table 1. Abbreviated Terms Used Throughout the Article

\begin{tabular}{|c|c|}
\hline AFDC & Aid to Families with Dependent Children \\
\hline ASEC & CPS Annual Social and Economic Supplement \\
\hline $\mathrm{CE}$ & Consumer Expenditure Survey (Bureau of Labor Statistics) \\
\hline CPI-U & Consumer Price Index for All Urban Consumers (Bureau of Labor Statistics) \\
\hline CPS & Current Population Survey (Bureau of Labor Statistics, U.S. Census Bureau) \\
\hline DER & Detailed Earnings Record (SSA) \\
\hline EITC & Earned Income Tax Credit \\
\hline HUD & U.S. Department of Housing and Urban Development \\
\hline IPW & Inverse Probability Weighting \\
\hline IRA & Individual Retirement Account \\
\hline IRS & Internal Revenue Service \\
\hline LIHEAP & Low Income Home Energy Assistance Program \\
\hline LIS & Luxembourg Income Study \\
\hline Numident & Numerical Identification File (SSA) \\
\hline OASDI & Old Age, Survivors, and Disability Insurance Program (Social Security) \\
\hline PA & Public Assistance \\
\hline PCE & Personal Consumption Expenditure \\
\hline PHUS & Payment History Update System (SSA) \\
\hline PIC & Public and Indian Housing Information Center (HUD) \\
\hline PSID & Panel Study of Income Dynamics (University of Michigan) \\
\hline PVS & Person Identification Validation System \\
\hline SIPP & Survey of Income and Program Participation (U.S. Census Bureau) \\
\hline SNAP & Supplemental Nutrition Assistance Program \\
\hline SPM & Supplemental Poverty Measure (U.S. Census Bureau) \\
\hline SSA & Social Security Administration \\
\hline SSI & Supplemental Security Income \\
\hline SSR & Supplemental Security Record (SSA) \\
\hline TANF & Temporary Assistance for Needy Families \\
\hline TRACS & Tenant Rental Assistance Certification System (HUD) \\
\hline TRIM & Transfer Income Model (Urban Institute) \\
\hline UI & Unemployment Insurance \\
\hline WC & Workers' Compensation \\
\hline WIC & Special Supplemental Nutrition Program for Women, Infants, and Children \\
\hline
\end{tabular}


Table 2. Administrative Data Sources

\begin{tabular}{|c|c|c|c|c|}
\hline Income Source & Administrative Source & Income Unit & Income Frequency & States Covered \\
\hline Earnings & DER (SSA) & Individual & Annual & All \\
\hline Asset Income & Form 1040 (IRS) & Tax Unit & Annual & All \\
\hline Retirement Distributions & Form 1099-R (IRS) & Individual & Annual & All \\
\hline OASDI & PHUS (SSA) & Individual & Monthly & All \\
\hline SSI & SSR (SSA) & Individual & Monthly & All \\
\hline EITC & Form 1040 (IRS) & Tax Unit & Annual & All \\
\hline SNAP & State Agencies & Household & Monthly & 11 States \\
\hline Housing Assistance & PIC \& TRACS (HUD) & Household & Monthly & All \\
\hline
\end{tabular}

Notes: This table shows - for each income source in the administrative data - the source of the data, the unit at which the dollar amounts are reported, the frequency at which the dollars are reported, and the states/years covered. Note that all of the administrative data, with the exception of SNAP, cover the universe of recipients in the United States. 
Table 3a. Percentage of Households in Extreme Poverty

\begin{tabular}{|c|c|c|c|c|c|c|}
\hline Specification & $\begin{array}{c}\text { (1) } \\
\text { All } \\
\text { Households }\end{array}$ & $\begin{array}{c}\text { (2) } \\
\text { Elderly }\end{array}$ & $\begin{array}{c}(3) \\
\text { Single } \\
\text { Parents }\end{array}$ & $\begin{array}{c}(4) \\
\text { Multiple } \\
\text { Parents }\end{array}$ & $\begin{array}{c}(5) \\
\text { Single } \\
\text { Childless }\end{array}$ & $\begin{array}{c}(6) \\
\text { Multiple } \\
\text { Childless }\end{array}$ \\
\hline Survey-Reported Cash & $\begin{array}{c}2.97 \\
(0.13)\end{array}$ & $\begin{array}{c}0.46 \\
(0.08)\end{array}$ & $\begin{array}{c}8.99 \\
(0.91)\end{array}$ & $\begin{array}{c}2.04 \\
(0.17)\end{array}$ & $\begin{array}{c}6.85 \\
(0.44)\end{array}$ & $\begin{array}{c}1.90 \\
(0.15)\end{array}$ \\
\hline \multicolumn{7}{|l|}{ Survey-Only Adjustments } \\
\hline Add In-Kind Transfers & $\begin{array}{c}2.04 \\
(0.11)\end{array}$ & $\begin{array}{c}0.42 \\
(0.08)\end{array}$ & $\begin{array}{c}2.80 \\
(0.41)\end{array}$ & $\begin{array}{l}1.16 \\
(0.13)\end{array}$ & $\begin{array}{c}5.58 \\
(0.41)\end{array}$ & $\begin{array}{c}1.58 \\
(0.14)\end{array}$ \\
\hline Correct Wage/Salary Earnings & $\begin{array}{c}1.83 \\
(0.10)\end{array}$ & $\begin{array}{c}0.37 \\
(0.08)\end{array}$ & $\begin{array}{c}2.66 \\
(0.40)\end{array}$ & $\begin{array}{c}0.94 \\
(0.12)\end{array}$ & $\begin{array}{c}5.12 \\
(0.39)\end{array}$ & $\begin{array}{c}1.39 \\
(0.13)\end{array}$ \\
\hline Correct Self-Employment Earnings & $\begin{array}{c}1.30 \\
(0.08)\end{array}$ & $\begin{array}{c}0.35 \\
(0.08)\end{array}$ & $\begin{array}{c}1.97 \\
(0.38)\end{array}$ & $\begin{array}{c}0.53 \\
(0.08)\end{array}$ & $\begin{array}{c}4.04 \\
(0.32)\end{array}$ & $\begin{array}{c}0.75 \\
(0.09)\end{array}$ \\
\hline Account for Assets* & $\begin{array}{c}0.84 \\
(0.07)\end{array}$ & $\begin{array}{c}0.13 \\
(0.05)\end{array}$ & $\begin{array}{c}1.35 \\
(0.32)\end{array}$ & $\begin{array}{c}0.27 \\
(0.06)\end{array}$ & $\begin{array}{c}2.86 \\
(0.31)\end{array}$ & $\begin{array}{c}0.44 \\
(0.07)\end{array}$ \\
\hline \multicolumn{7}{|l|}{ Administrative Data Adjustments } \\
\hline Correct Earnings & $\begin{array}{c}0.42 \\
(0.05)\end{array}$ & $\begin{array}{c}0.11 \\
(0.04)\end{array}$ & $\begin{array}{c}0.54 \\
(0.20)\end{array}$ & $\begin{array}{c}0.11 \\
(0.04)\end{array}$ & $\begin{array}{l}1.63 \\
(0.22)\end{array}$ & $\begin{array}{c}0.08 \\
(0.03)\end{array}$ \\
\hline Correct Assets/Retirement Income & $\begin{array}{c}0.35 \\
(0.04)\end{array}$ & $\begin{array}{c}0.06 \\
(0.03)\end{array}$ & $\begin{array}{c}0.46 \\
(0.19)\end{array}$ & $\begin{array}{c}0.11 \\
(0.04)\end{array}$ & $\begin{array}{l}1.35 \\
(0.19)\end{array}$ & $\begin{array}{c}0.08 \\
(0.03)\end{array}$ \\
\hline Add EITC & $\begin{array}{c}0.31 \\
(0.04)\end{array}$ & $\begin{array}{c}0.06 \\
(0.03)\end{array}$ & $\begin{array}{c}0.10 \\
(0.07)\end{array}$ & $\begin{array}{c}0.08 \\
(0.03)\end{array}$ & $\begin{array}{c}1.29 \\
(0.19)\end{array}$ & $\begin{array}{c}0.08 \\
(0.03)\end{array}$ \\
\hline Correct OASDI/SSI & $\begin{array}{c}0.27 \\
(0.04)\end{array}$ & $\begin{array}{c}0.01 \\
(0.01)\end{array}$ & $\begin{array}{c}0.10 \\
(0.07)\end{array}$ & $\begin{array}{c}0.06 \\
(0.03)\end{array}$ & $\begin{array}{c}1.19 \\
(0.18)\end{array}$ & $\begin{array}{c}0.07 \\
(0.03)\end{array}$ \\
\hline Correct Housing Assistance & $\begin{array}{c}0.27 \\
(0.04)\end{array}$ & $\begin{array}{c}0.01 \\
(0.01)\end{array}$ & $\begin{array}{c}0.10 \\
(0.07)\end{array}$ & $\begin{array}{c}0.06 \\
(0.03)\end{array}$ & $\begin{array}{c}1.18 \\
(0.18)\end{array}$ & $\begin{array}{c}0.07 \\
(0.03)\end{array}$ \\
\hline Correct SNAP & $\begin{array}{c}0.24 \\
(0.04)\end{array}$ & $\begin{array}{c}0.00 \\
(0.00)\end{array}$ & $\begin{array}{c}0.00 \\
(0.00)\end{array}$ & $\begin{array}{c}0.00 \\
(0.00)\end{array}$ & $\begin{array}{c}1.12 \\
(0.18)\end{array}$ & $\begin{array}{c}0.07 \\
(0.03)\end{array}$ \\
\hline \multicolumn{7}{|l|}{ Population Estimates } \\
\hline $\begin{array}{l}\text { U.S. } \\
\text { SNAP States }\end{array}$ & $\begin{array}{r}118,600,000 \\
34,360,000\end{array}$ & $\begin{array}{r}26,070,000 \\
7,356,000\end{array}$ & $\begin{array}{l}6,917,000 \\
2,035,000\end{array}$ & $\begin{array}{r}31,670,000 \\
9,290,000\end{array}$ & $\begin{array}{r}22,530,000 \\
6,642,000\end{array}$ & $\begin{array}{r}31,430,000 \\
9,036,000\end{array}$ \\
\hline \multicolumn{7}{|l|}{ Sample Sizes } \\
\hline $\begin{array}{l}\text { U.S. } \\
\text { SNAP States }\end{array}$ & $\begin{array}{l}31,500 \\
10,000\end{array}$ & $\begin{array}{l}8,000 \\
2,500\end{array}$ & $\begin{array}{r}1,500 \\
500\end{array}$ & $\begin{array}{l}8,300 \\
2,700\end{array}$ & $\begin{array}{l}5,200 \\
1,600\end{array}$ & $\begin{array}{l}8,500 \\
2,700\end{array}$ \\
\hline
\end{tabular}

$*$ Real estate equity $>\$ 25,000$, liquid assets $>\$ 5,000$, or total net worth $>\$ 50,000$.

Source: Wave 9 of the 2008 SIPP Panel, spanning January-July 2011. Administrative data sources described in text.

Notes: Standard errors calculated using replicate weights in parentheses. Households in "extreme poverty" are those with average income across the four months of the wave less than or equal to $\$ 2 /$ person/day. Households with negative incomes in any month are defined as not in extreme poverty. Sample consists of households with at least one member with a PIK and present in reference month 4 . Reference month 4 survey weights are adjusted for missing PIKs. When including housing assistance, all households that receive public housing or housing subsidies are defined as not in extreme poverty. The number of hours that each person worked in a month is calculated as [average hours per week worked this reference period in a paid job] $\times$ [number of weeks worked this month in a paid job]. Hours worked in a month are then multiplied by the federal minimum wage (\$7.25) to estimate lower-bound earnings for the month, and the estimated lower-bound earnings are summed across all household members. We do not include unpaid family workers in this calculation. Assets are as reported in the Wave 10 topical module (or Wave 7, if a household does not match to Wave 10). Counts rounded according to disclosure avoidance rules. 
Table 3b. Percentage of Individuals in Extreme Poverty

\begin{tabular}{|c|c|c|c|c|c|c|}
\hline Specification & $\begin{array}{c}\text { (1) } \\
\text { All } \\
\text { Households }\end{array}$ & $\begin{array}{c}\text { (2) } \\
\text { EIderly }\end{array}$ & $\begin{array}{c}\text { (3) } \\
\text { Single Parents }\end{array}$ & $\begin{array}{c}(4) \\
\text { Multiple } \\
\text { Parents }\end{array}$ & $\begin{array}{c}(5) \\
\text { Single } \\
\text { Childless } \\
\end{array}$ & $\begin{array}{c}(6) \\
\text { Multiple } \\
\text { Childless } \\
\end{array}$ \\
\hline Survey-Reported Cash & $\begin{array}{c}2.60 \\
(0.14)\end{array}$ & $\begin{array}{c}0.47 \\
(0.21)\end{array}$ & $\begin{array}{c}9.56 \\
(0.98)\end{array}$ & $\begin{array}{c}2.11 \\
(0.17)\end{array}$ & $\begin{array}{c}6.85 \\
(0.44)\end{array}$ & $\begin{array}{c}1.83 \\
(0.15)\end{array}$ \\
\hline \multicolumn{7}{|l|}{ Survey Only Adjustments } \\
\hline Add In-Kind Transfers & $\begin{array}{c}1.57 \\
(0.09)\end{array}$ & $\begin{array}{c}0.43 \\
(0.21)\end{array}$ & $\begin{array}{c}2.65 \\
(0.45)\end{array}$ & $\begin{array}{c}1.20 \\
(0.14)\end{array}$ & $\begin{array}{c}5.58 \\
(0.41)\end{array}$ & $\begin{array}{c}1.50 \\
(0.14)\end{array}$ \\
\hline Correct Wage/Salary Earnings & $\begin{array}{c}1.37 \\
(0.09)\end{array}$ & $\begin{array}{c}0.36 \\
(0.18)\end{array}$ & $\begin{array}{c}2.53 \\
(0.44)\end{array}$ & $\begin{array}{c}0.95 \\
(0.12)\end{array}$ & $\begin{array}{c}5.12 \\
(0.39)\end{array}$ & $\begin{array}{c}1.33 \\
(0.14)\end{array}$ \\
\hline Correct Self-Employment Earnings & $\begin{array}{c}0.90 \\
(0.06)\end{array}$ & $\begin{array}{c}0.35 \\
(0.18)\end{array}$ & $\begin{array}{c}1.93 \\
(0.45)\end{array}$ & $\begin{array}{c}0.52 \\
(0.09)\end{array}$ & $\begin{array}{c}4.04 \\
(0.32)\end{array}$ & $\begin{array}{c}0.75 \\
(0.11)\end{array}$ \\
\hline Account for Assets* & $\begin{array}{c}0.57 \\
(0.05)\end{array}$ & $\begin{array}{c}0.11 \\
(0.04)\end{array}$ & $\begin{array}{c}1.49 \\
(0.45)\end{array}$ & $\begin{array}{c}0.28 \\
(0.06)\end{array}$ & $\begin{array}{c}2.86 \\
(0.31)\end{array}$ & $\begin{array}{c}0.46 \\
(0.10)\end{array}$ \\
\hline \multicolumn{7}{|l|}{ Administrative Data Adjustments } \\
\hline Correct Earnings & $\begin{array}{c}0.24 \\
(0.03)\end{array}$ & $\begin{array}{c}0.09 \\
(0.04)\end{array}$ & $\begin{array}{c}0.64 \\
(0.28)\end{array}$ & $\begin{array}{c}0.10 \\
(0.04)\end{array}$ & $\begin{array}{c}1.63 \\
(0.22)\end{array}$ & $\begin{array}{c}0.09 \\
(0.04)\end{array}$ \\
\hline Correct Assets/Retirement Income & $\begin{array}{c}0.21 \\
(0.03)\end{array}$ & $\begin{array}{c}0.06 \\
(0.03)\end{array}$ & $\begin{array}{c}0.56 \\
(0.25)\end{array}$ & $\begin{array}{c}0.10 \\
(0.04)\end{array}$ & $\begin{array}{c}1.35 \\
(0.19)\end{array}$ & $\begin{array}{c}0.09 \\
(0.04)\end{array}$ \\
\hline Add EITC & $\begin{array}{c}0.17 \\
(0.03)\end{array}$ & $\begin{array}{c}0.06 \\
(0.03)\end{array}$ & $\begin{array}{c}0.12 \\
(0.10)\end{array}$ & $\begin{array}{c}0.07 \\
(0.03)\end{array}$ & $\begin{array}{c}1.29 \\
(0.19)\end{array}$ & $\begin{array}{c}0.09 \\
(0.04)\end{array}$ \\
\hline Correct OASDI/SSI & $\begin{array}{c}0.14 \\
(0.02)\end{array}$ & $\begin{array}{c}0.01 \\
(0.01)\end{array}$ & $\begin{array}{c}0.12 \\
(0.10)\end{array}$ & $\begin{array}{c}0.05 \\
(0.02)\end{array}$ & $\begin{array}{c}1.19 \\
(0.18)\end{array}$ & $\begin{array}{c}0.07 \\
(0.04)\end{array}$ \\
\hline Correct Housing Assistance & $\begin{array}{c}0.14 \\
(0.02)\end{array}$ & $\begin{array}{c}0.01 \\
(0.01)\end{array}$ & $\begin{array}{c}0.12 \\
(0.10)\end{array}$ & $\begin{array}{c}0.05 \\
(0.02)\end{array}$ & $\begin{array}{l}1.18 \\
(0.18)\end{array}$ & $\begin{array}{c}0.07 \\
(0.04)\end{array}$ \\
\hline Correct SNAP & $\begin{array}{c}0.11 \\
(0.02)\end{array}$ & $\begin{array}{c}0.00 \\
(0.00)\end{array}$ & $\begin{array}{c}0.00 \\
(0.00)\end{array}$ & $\begin{array}{c}0.00 \\
(0.00)\end{array}$ & $\begin{array}{c}1.12 \\
(0.18)\end{array}$ & $\begin{array}{c}0.07 \\
(0.04)\end{array}$ \\
\hline \multicolumn{7}{|l|}{ Population Estimates } \\
\hline $\begin{array}{l}\text { U.S. } \\
\text { SNAP States }\end{array}$ & $\begin{array}{r}305,600,000 \\
88,610,000\end{array}$ & $\begin{array}{l}45,540,000 \\
13,030,000\end{array}$ & $\begin{array}{r}18,770,000 \\
5,358,000\end{array}$ & $\begin{array}{r}138,300,000 \\
39,990,000\end{array}$ & $\begin{array}{r}22,530,000 \\
6,642,000\end{array}$ & $\begin{array}{l}80,460,000 \\
23,590,000\end{array}$ \\
\hline $\begin{array}{l}\text { Sample Sizes } \\
\text { U.S. } \\
\text { SNAP States }\end{array}$ & $\begin{array}{l}82,500 \\
26,500 \\
\end{array}$ & $\begin{array}{r}14,500 \\
4,500 \\
\end{array}$ & $\begin{array}{l}4,500 \\
1,400 \\
\end{array}$ & $\begin{array}{l}37,000 \\
12,000 \\
\end{array}$ & $\begin{array}{l}5,500 \\
1,700\end{array}$ & $\begin{array}{r}21,000 \\
6,700 \\
\end{array}$ \\
\hline
\end{tabular}

$*$ Real estate equity $>\$ 25,000$, liquid assets $>\$ 5,000$, or total net worth $>\$ 50,000$.

Source: Wave 9 of the 2008 SIPP Panel, spanning January-July 2011. Administrative data sources described in text.

Notes: Standard errors calculated using replicate weights in parentheses. Individuals in "extreme poverty" are those living in households with average income across the four months of the wave less than or equal to $\$ 2 /$ person/day. Individuals with negative household incomes in any month are defined as not in extreme poverty. Sample consists of individuals living in households with at least one member with a PIK and present in reference month 4. Reference month 4 survey weights are adjusted for missing PIKs. When including housing assistance, all households that receive public housing or housing subsidies are defined as not in extreme poverty. The number of hours that each person worked in a month is calculated as [average hours per week worked this reference period in a paid job] $\times$ [number of weeks worked this month in a paid job]. Hours worked in a month are then multiplied by the federal minimum wage (\$7.25) to estimate lower-bound earnings for the month, and the estimated lower-bound earnings are summed across all household members. We do not include unpaid family workers in this calculation. Assets are as reported in the Wave 10 topical module (or Wave 7, if a household does not match to Wave 10). Counts rounded according to disclosure avoidance rules. 
Table 4. Income Receipt Rates (\%) for Remaining Extreme Poor Households After Survey-Only Adjustments

\begin{tabular}{|c|c|c|c|c|c|c|}
\hline Source & $\begin{array}{c}\text { (1) } \\
\text { All } \\
\text { Households }\end{array}$ & $\begin{array}{c}\text { (2) } \\
\text { Elderly }\end{array}$ & $\begin{array}{c}\text { (3) } \\
\text { Single } \\
\text { Parents }\end{array}$ & $\begin{array}{c}\text { (4) } \\
\text { Multiple } \\
\text { Parents }\end{array}$ & $\begin{array}{c}\text { (5) } \\
\text { Single } \\
\text { Individuals } \\
\end{array}$ & $\begin{array}{c}\text { (6) } \\
\text { Multiple } \\
\text { Adults }\end{array}$ \\
\hline Earnings & $\begin{array}{l}55.93 \\
(3.34)\end{array}$ & $\begin{array}{c}15.41 \\
(14.97)\end{array}$ & $\begin{array}{c}74.76 \\
(10.01)\end{array}$ & $\begin{array}{c}70.15 \\
(11.57)\end{array}$ & $\begin{array}{l}47.92 \\
(4.29)\end{array}$ & $\begin{array}{l}81.24 \\
(7.05)\end{array}$ \\
\hline Asset Income & $\begin{array}{c}9.77 \\
(2.30)\end{array}$ & $\begin{array}{c}15.41 \\
(14.97)\end{array}$ & $\begin{array}{c}0.00 \\
(0.00)\end{array}$ & $\begin{array}{c}6.67 \\
(3.73)\end{array}$ & $\begin{array}{c}9.17 \\
(2.89)\end{array}$ & $\begin{array}{l}19.61 \\
(7.93)\end{array}$ \\
\hline Retirement Distributions & $\begin{array}{l}11.75 \\
(2.25)\end{array}$ & $\begin{array}{c}43.08 \\
(18.77)\end{array}$ & $\begin{array}{c}6.59 \\
(7.07)\end{array}$ & $\begin{array}{c}3.90 \\
(4.04)\end{array}$ & $\begin{array}{l}12.75 \\
(3.40)\end{array}$ & $\begin{array}{c}7.88 \\
(4.06)\end{array}$ \\
\hline OASDI & $\begin{array}{c}6.14 \\
(1.69)\end{array}$ & $\begin{array}{c}58.50 \\
(19.83)\end{array}$ & $\begin{array}{c}0.00 \\
(0.00)\end{array}$ & $\begin{array}{c}7.18 \\
(5.04)\end{array}$ & $\begin{array}{c}5.15 \\
(2.06)\end{array}$ & $\begin{array}{c}1.58 \\
(1.71)\end{array}$ \\
\hline SSI & $\begin{array}{c}2.83 \\
(1.18)\end{array}$ & $\begin{array}{c}35.47 \\
(19.21)\end{array}$ & $\begin{array}{c}0.00 \\
(0.00)\end{array}$ & $\begin{array}{l}14.46 \\
(9.00)\end{array}$ & $\begin{array}{c}0.00 \\
(0.00)\end{array}$ & $\begin{array}{c}2.69 \\
(2.20)\end{array}$ \\
\hline Housing & $\begin{array}{c}3.55 \\
(1.47)\end{array}$ & $\begin{array}{c}20.60 \\
(15.54)\end{array}$ & $\begin{array}{c}1.11 \\
(1.08)\end{array}$ & $\begin{array}{l}11.00 \\
(9.69)\end{array}$ & $\begin{array}{c}2.79 \\
(1.69)\end{array}$ & $\begin{array}{c}0.00 \\
(0.00)\end{array}$ \\
\hline EITC & $\begin{array}{l}30.19 \\
(3.40)\end{array}$ & $\begin{array}{c}0.00 \\
(0.00)\end{array}$ & $\begin{array}{c}67.95 \\
(11.41)\end{array}$ & $\begin{array}{l}73.34 \\
(9.18)\end{array}$ & $\begin{array}{l}19.19 \\
(3.74)\end{array}$ & $\begin{array}{c}36.18 \\
(11.38)\end{array}$ \\
\hline SNAP & $\begin{array}{l}19.06 \\
(4.26)\end{array}$ & & $\begin{array}{c}61.40 \\
(14.34)\end{array}$ & $\begin{array}{c}73.40 \\
(19.23)\end{array}$ & $\begin{array}{c}3.80 \\
(2.49)\end{array}$ & $\begin{array}{c}21.79 \\
(11.19)\end{array}$ \\
\hline Any Transfer & $\begin{array}{l}42.68 \\
(6.81)\end{array}$ & $\begin{array}{c}89.51 \\
(11.12)\end{array}$ & $\begin{array}{c}69.26 \\
(20.81)\end{array}$ & $\begin{array}{c}78.73 \\
(20.08)\end{array}$ & $\begin{array}{c}30.97 \\
(8.14)\end{array}$ & $\begin{array}{c}51.40 \\
(18.07)\end{array}$ \\
\hline
\end{tabular}

Source: Wave 9 of the 2008 SIPP Panel, spanning January-July 2011. Administrative data sources described in text.

Notes: Standard errors calculated using replicate weights in parentheses. These shares reflect the percent of households among the remaining extreme poor after the survey-only adjustments that receive each source of income in the administrative data. Sample consists of households with at least one member with a PIK and present in reference month 4 . Reference month 4 survey weights are adjusted for missing PIKs. All income sources are calculated over all 50 states except for SNAP and "Any Transfer", which are calculated over the 11 states for which we have administrative SNAP data. For the elderly, we omit SNAP from the "Any Transfer" category. 
Table 5. Selected Demographics for Extreme Poor Subgroups and Comparison Households

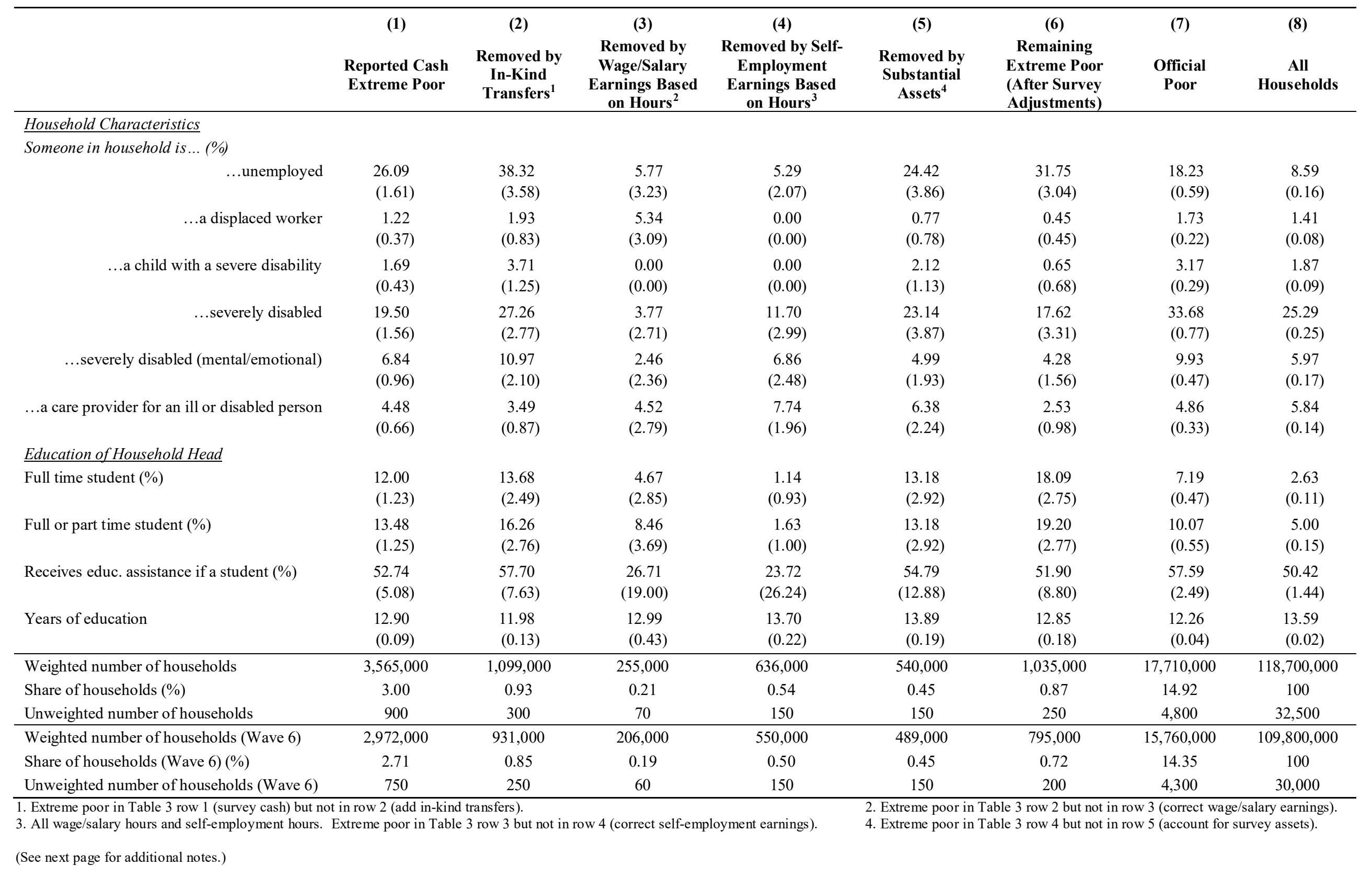


Table 5. Selected Demographics for Extreme Poor Subgroups and Comparison Households (continued)

\begin{tabular}{|c|c|c|c|c|c|c|c|c|}
\hline & $\begin{array}{c}\text { (1) } \\
\text { Reported Cash } \\
\text { Extreme Poor }\end{array}$ & $\begin{array}{c}(2) \\
\text { Removed by } \\
\text { In-Kind } \\
\text { Transfers }{ }^{1}\end{array}$ & $\begin{array}{c}\text { (3) } \\
\text { Removed by } \\
\text { Wage/Salary } \\
\text { Earnings Based } \\
\text { on Hours } \\
\end{array}$ & $\begin{array}{c}(4) \\
\text { Removed by Self- } \\
\text { Employment } \\
\text { Earnings Based } \\
\text { on Hours }{ }^{3} \\
\end{array}$ & $\begin{array}{c}\text { (5) } \\
\text { Removed by } \\
\text { Substantial } \\
\text { Assets }^{4}\end{array}$ & $\begin{array}{c}\text { (6) } \\
\text { Remaining } \\
\text { Extreme Poor } \\
\text { (After Survey } \\
\text { Adjustments) } \\
\end{array}$ & $\begin{array}{c}\text { (7) } \\
\text { Official } \\
\text { Poor }\end{array}$ & $\begin{array}{c}\text { (8) } \\
\text { All } \\
\text { Households }\end{array}$ \\
\hline \multicolumn{9}{|l|}{ Health Insurance of Household Head (\%) } \\
\hline Medicaid & $\begin{array}{l}19.07 \\
(1.56)\end{array}$ & $\begin{array}{l}49.93 \\
(3.66)\end{array}$ & $\begin{array}{c}1.87 \\
(1.95)\end{array}$ & $\begin{array}{c}4.41 \\
(1.79)\end{array}$ & $\begin{array}{c}3.21 \\
(1.57)\end{array}$ & $\begin{array}{c}7.82 \\
(1.75)\end{array}$ & $\begin{array}{c}32.01 \\
(0.69)\end{array}$ & $\begin{array}{c}9.40 \\
(0.18)\end{array}$ \\
\hline Private Insurance & $\begin{array}{c}28.62 \\
(1.89)\end{array}$ & $\begin{array}{c}4.12 \\
(1.20)\end{array}$ & $\begin{array}{l}57.49 \\
(6.46)\end{array}$ & $\begin{array}{c}49.87 \\
(4.49)\end{array}$ & $\begin{array}{l}53.60 \\
(4.45)\end{array}$ & $\begin{array}{l}21.47 \\
(3.35)\end{array}$ & $\begin{array}{c}25.70 \\
(0.78)\end{array}$ & $\begin{array}{c}69.73 \\
(0.29)\end{array}$ \\
\hline Medicaid or Medicare or Private Insurance & $\begin{array}{l}48.08 \\
(2.16)\end{array}$ & $\begin{array}{c}53.46 \\
(3.68)\end{array}$ & $\begin{array}{c}60.24 \\
(6.35)\end{array}$ & $\begin{array}{l}55.40 \\
(4.55)\end{array}$ & $\begin{array}{l}58.04 \\
(4.55)\end{array}$ & $\begin{array}{c}29.69 \\
(3.52)\end{array}$ & $\begin{array}{l}62.98 \\
(0.74)\end{array}$ & $\begin{array}{c}84.76 \\
(0.23)\end{array}$ \\
\hline \multicolumn{9}{|l|}{ Assets (\%) } \\
\hline Own a home & $\begin{array}{c}33.95 \\
(1.66)\end{array}$ & $\begin{array}{l}14.24 \\
(2.09)\end{array}$ & $\begin{array}{c}32.37 \\
(5.83)\end{array}$ & $\begin{array}{l}69.21 \\
(3.84)\end{array}$ & $\begin{array}{l}72.79 \\
(3.88)\end{array}$ & $\begin{array}{c}9.36 \\
(2.25)\end{array}$ & $\begin{array}{l}31.25 \\
(0.76)\end{array}$ & $\begin{array}{c}61.73 \\
(0.26)\end{array}$ \\
\hline Total real estate equity $>\$ 25,000$ & $\begin{array}{l}26.31 \\
(1.57)\end{array}$ & $\begin{array}{c}9.95 \\
(1.86)\end{array}$ & $\begin{array}{c}27.43 \\
(5.77)\end{array}$ & $\begin{array}{l}48.41 \\
(3.79)\end{array}$ & $\begin{array}{l}74.96 \\
(3.76)\end{array}$ & $\begin{array}{c}0.00 \\
(0.00)\end{array}$ & $\begin{array}{l}24.38 \\
(0.70)\end{array}$ & $\begin{array}{c}50.08 \\
(0.27)\end{array}$ \\
\hline Own a car, van, or truck & $\begin{array}{l}64.69 \\
(1.91)\end{array}$ & $\begin{array}{l}47.40 \\
(3.55)\end{array}$ & $\begin{array}{l}69.28 \\
(5.97)\end{array}$ & $\begin{array}{l}89.71 \\
(2.26)\end{array}$ & $\begin{array}{l}78.41 \\
(3.59)\end{array}$ & $\begin{array}{l}58.40 \\
(4.20)\end{array}$ & $\begin{array}{c}63.57 \\
(0.78)\end{array}$ & $\begin{array}{c}84.37 \\
(0.24)\end{array}$ \\
\hline Liquid assets $>\$ 5,000$ & $\begin{array}{l}11.68 \\
(1.17)\end{array}$ & $\begin{array}{c}1.15 \\
(0.68)\end{array}$ & $\begin{array}{c}6.15 \\
(3.21)\end{array}$ & $\begin{array}{c}20.65 \\
(3.71)\end{array}$ & $\begin{array}{c}43.33 \\
(3.98)\end{array}$ & $\begin{array}{c}0.00 \\
(0.00)\end{array}$ & $\begin{array}{c}8.50 \\
(0.44)\end{array}$ & $\begin{array}{c}33.05 \\
(0.36)\end{array}$ \\
\hline Total assets $>\$ 50,000$ & $\begin{array}{l}31.07 \\
(1.75)\end{array}$ & $\begin{array}{c}9.31 \\
(1.77)\end{array}$ & $\begin{array}{c}31.92 \\
(6.31)\end{array}$ & $\begin{array}{l}67.57 \\
(4.62)\end{array}$ & $\begin{array}{l}81.79 \\
(3.17)\end{array}$ & $\begin{array}{c}0.00 \\
(0.00)\end{array}$ & $\begin{array}{l}25.37 \\
(0.69)\end{array}$ & $\begin{array}{l}55.29 \\
(0.27)\end{array}$ \\
\hline Total assets $>\$ 100,000$ & $\begin{array}{l}21.92 \\
(1.45)\end{array}$ & $\begin{array}{c}4.27 \\
(1.16)\end{array}$ & $\begin{array}{c}24.07 \\
(5.79)\end{array}$ & $\begin{array}{l}51.99 \\
(4.33)\end{array}$ & $\begin{array}{l}63.46 \\
(4.43)\end{array}$ & $\begin{array}{c}0.00 \\
(0.00)\end{array}$ & $\begin{array}{l}18.01 \\
(0.55)\end{array}$ & $\begin{array}{c}43.88 \\
(0.26)\end{array}$ \\
\hline Total assets $>\$ 250,000$ & $\begin{array}{l}12.02 \\
(1.27)\end{array}$ & $\begin{array}{c}1.29 \\
(0.71)\end{array}$ & $\begin{array}{c}12.19 \\
(4.11)\end{array}$ & $\begin{array}{l}33.65 \\
(4.36)\end{array}$ & $\begin{array}{l}31.39 \\
(4.33)\end{array}$ & $\begin{array}{c}0.00 \\
(0.00)\end{array}$ & $\begin{array}{c}8.78 \\
(0.44)\end{array}$ & $\begin{array}{c}25.99 \\
(0.22)\end{array}$ \\
\hline Total assets $>\$ 500,000$ & $\begin{array}{c}6.09 \\
(0.92)\end{array}$ & $\begin{array}{c}0.33 \\
(0.32)\end{array}$ & $\begin{array}{c}3.27 \\
(2.28)\end{array}$ & $\begin{array}{c}20.47 \\
(3.53)\end{array}$ & $\begin{array}{l}13.91 \\
(3.57)\end{array}$ & $\begin{array}{c}0.00 \\
(0.00)\end{array}$ & $\begin{array}{c}3.75 \\
(0.32)\end{array}$ & $\begin{array}{l}12.86 \\
(0.20)\end{array}$ \\
\hline Weighted number of households & $3,565,000$ & $1,099,000$ & 255,000 & 636,000 & 540,000 & $1,035,000$ & $17,710,000$ & $118,700,000$ \\
\hline Share of households (\%) & 3.00 & 0.93 & 0.21 & 0.54 & 0.45 & 0.87 & 14.92 & 100 \\
\hline Unweighted number of households & 900 & 300 & 70 & 150 & 150 & 250 & 4,800 & 32,500 \\
\hline Weighted number of households (Wave 6) & $2,972,000$ & 931,000 & 206,000 & 550,000 & 489,000 & 795,000 & $15,760,000$ & $109,800,000$ \\
\hline Share of households (Wave 6) (\%) & 2.71 & 0.85 & 0.19 & 0.50 & 0.45 & 0.72 & 14.35 & 100 \\
\hline Unweighted number of households (Wave 6) & 750 & 250 & 60 & 150 & 150 & 200 & 4,300 & 30,000 \\
\hline
\end{tabular}

1. Extreme poor in Table 3 row 1 (survey cash) but not in row 2 (add in-kind transfers).

2. Extreme poor in Table 3 row 2 but not in row 3 (correct wage/salary earnings)

3. All wage/salary hours and self-employment hours. Extreme poor in Table 3 row 3 but not in row 4 (correct self-employment earnings).

4. Extreme poor in Table 3 row 4 but not in row 5 (account for survey assets).

Source: Wave 9 of the public use 2008 SIPP Panel, spanning January-July 2011.

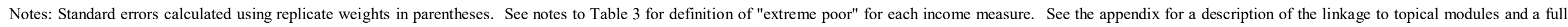

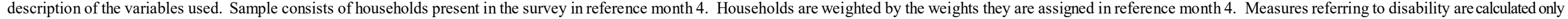
over households that appear in Wave 6 (from the Wave 6 topical module). Counts rounded according to disclosure avoidance rules. 
Table 6. Comparison of CPS and SIPP Extreme Poverty Estimates for All Households

\begin{tabular}{|c|c|c|c|c|c|}
\hline \multirow[b]{3}{*}{ Specification } & \multirow{3}{*}{$\begin{array}{c}\text { (1) } \\
\text { CPS } \\
\text { Rate (\%) } \\
\end{array}$} & \multirow{2}{*}{\multicolumn{2}{|c|}{$\begin{array}{cc}(2) & (3) \\
\text { SIPP - Aligned Adjustments }\end{array}$}} & \multirow{2}{*}{\multicolumn{2}{|c|}{$\begin{array}{cc}\text { (4) } & (5) \\
\text { SIPP }- \text { Original Adjustments }\end{array}$}} \\
\hline & & & & & \\
\hline & & Rate (\%) & $\begin{array}{l}\text { Diff. in Rates, } \\
\text { CPS - SIPP (pp) }\end{array}$ & Rate $(\%)$ & $\begin{array}{l}\text { Diff. in Rates, } \\
\text { CPS - SIPP (pp) }\end{array}$ \\
\hline Survey-Reported Cash & $\begin{array}{c}2.08 \\
(0.08)\end{array}$ & $\begin{array}{c}2.97 \\
(0.13)\end{array}$ & $-0.89 * * *$ & $\begin{array}{c}2.97 \\
(0.13)\end{array}$ & $-0.89 * * *$ \\
\hline \multicolumn{6}{|l|}{ Survey Only Adjustments } \\
\hline Correct Wage/Salary Earnings & $\begin{array}{l}2.05 \\
(0.06)\end{array}$ & $\begin{array}{c}2.68 \\
(0.13)\end{array}$ & $-0.63 * * *$ & $\begin{array}{l}2.68 \\
(0.13)\end{array}$ & $-0.63 * * *$ \\
\hline Correct Self-Employment Earnings & $\begin{array}{c}2.03 \\
(0.06)\end{array}$ & $\begin{array}{c}2.07 \\
(0.11)\end{array}$ & -0.04 & $\begin{array}{c}2.07 \\
(0.11)\end{array}$ & -0.04 \\
\hline Add In-Kind Transfers ${ }^{1}$ & $\begin{array}{l}1.35 \\
(0.06)\end{array}$ & $\begin{array}{l}1.30 \\
(0.08)\end{array}$ & 0.05 & $\begin{array}{c}1.30 \\
(0.08)\end{array}$ & 0.05 \\
\hline Account for Assets ${ }^{2}$ & $\begin{array}{c}0.80 \\
(0.05)\end{array}$ & $\begin{array}{c}0.96 \\
(0.07)\end{array}$ & $-0.16^{*}$ & $\begin{array}{c}0.84 \\
(0.07)\end{array}$ & -0.04 \\
\hline \multicolumn{6}{|l|}{ Administrative Data Adjustments } \\
\hline Correct Earnings & $\begin{array}{c}0.41 \\
(0.04)\end{array}$ & $\begin{array}{c}0.48 \\
(0.05)\end{array}$ & -0.07 & $\begin{array}{c}0.42 \\
(0.05)\end{array}$ & -0.01 \\
\hline Correct Assets/Retirement Income & $\begin{array}{c}0.34 \\
(0.03)\end{array}$ & $\begin{array}{c}0.40 \\
(0.04)\end{array}$ & -0.05 & $\begin{array}{c}0.35 \\
(0.04)\end{array}$ & -0.01 \\
\hline Add EITC & $\begin{array}{c}0.34 \\
(0.03)\end{array}$ & $\begin{array}{c}0.35 \\
(0.04)\end{array}$ & -0.01 & $\begin{array}{c}0.31 \\
(0.04)\end{array}$ & 0.03 \\
\hline Correct OASDI/SSI & $\begin{array}{c}0.23 \\
(0.03)\end{array}$ & $\begin{array}{c}0.31 \\
(0.04)\end{array}$ & $-0.08^{*}$ & $\begin{array}{c}0.27 \\
(0.04)\end{array}$ & -0.04 \\
\hline Correct Housing Assistance & $\begin{array}{c}0.21 \\
(0.03)\end{array}$ & $\begin{array}{c}0.31 \\
(0.04)\end{array}$ & $-0.10 * *$ & $\begin{array}{c}0.27 \\
(0.04)\end{array}$ & -0.06 \\
\hline Correct SNAP & $\begin{array}{r}0.18 \\
(0.03) \\
\end{array}$ & $\begin{array}{r}0.29 \\
(0.04) \\
\end{array}$ & $-0.11 * *$ & $\begin{array}{r}0.24 \\
(0.04) \\
\end{array}$ & -0.06 \\
\hline
\end{tabular}

$* * * \mathrm{p}<0.01,{ }^{* *} \mathrm{p}<0.05,{ }^{*} \mathrm{p}<0.1$

1. SNAP, WIC, and housing assistance in SIPP (original adjustments). SNAP and housing in CPS, SIPP (aligned adjustments).

2. For SIPP (original adjustments), owns real estate equity $>\$ 25,000$, liquid assets $>\$ 5,000$, or total net worth $>\$ 50,000$. For CPS and SIPP (aligned adjustments), household has home value $>\$ 25,000$ and has no mortgage, or has home value $>\$ 100,000$ and has a mortgage.

Source: For SIPP, we use Wave 9 of the 2008 SIPP Panel, spanning January-July 2011. For CPS, we use the 2012 CPS ASEC corresponding to reference year 2011. Administrative data sources described in text.

Notes: Standard errors calculated using replicate weights in parentheses. For SIPP, sample consists of households with at least one member with a PIK and present in reference month 4. Reference month 4 survey weights are adjusted for missing PIKs. For CPS, sample consists of households with at least one member with a PIK and no members that are whole imputes. Survey weights adjusted for missing PIKs and whole imputes. 
Table 7. Robustness Checks (Percentage of Households in Extreme Poverty)

\begin{tabular}{|c|c|c|c|}
\hline Specification & $\begin{array}{c}\text { (1) } \\
\text { \$2/Day: } \\
\text { Half Minimum Wage }\end{array}$ & $\begin{array}{c}\text { (2) } \\
\text { \$2/Day: } \\
\text { No Housing Assistance }\end{array}$ & $\begin{array}{c}\text { (3) } \\
\text { \$4/Day }\end{array}$ \\
\hline Survey-Reported Cash & $\begin{array}{c}2.97 \\
(0.13)\end{array}$ & $\begin{array}{c}2.97 \\
(0.13)\end{array}$ & $\begin{array}{c}3.68 \\
(0.13)\end{array}$ \\
\hline \multicolumn{4}{|l|}{ Survey Only Adjustments } \\
\hline Add In-Kind Transfers & $\begin{array}{c}2.04 \\
(0.11)\end{array}$ & $\begin{array}{c}2.08 \\
(0.10)\end{array}$ & $\begin{array}{c}2.48 \\
(0.12)\end{array}$ \\
\hline Correct Wage/Salary Earnings & $\begin{array}{c}1.83 \\
(0.10)\end{array}$ & $\begin{array}{c}1.86 \\
(0.10)\end{array}$ & $\begin{array}{c}2.17 \\
(0.11)\end{array}$ \\
\hline Correct Self-Employment Earnings & $\begin{array}{c}1.31 \\
(0.08)\end{array}$ & $\begin{array}{c}1.32 \\
(0.07)\end{array}$ & $\begin{array}{c}1.54 \\
(0.08)\end{array}$ \\
\hline Account for Assets & $\begin{array}{c}0.84 \\
(0.07)\end{array}$ & $\begin{array}{c}0.86 \\
(0.07)\end{array}$ & $\begin{array}{c}1.00 \\
(0.07)\end{array}$ \\
\hline \multicolumn{4}{|l|}{ Administrative Data Adjustments } \\
\hline Correct Earnings & $\begin{array}{c}0.42 \\
(0.05)\end{array}$ & $\begin{array}{c}0.43 \\
(0.05)\end{array}$ & $\begin{array}{c}0.50 \\
(0.05)\end{array}$ \\
\hline Correct Assets/Retirement Income & $\begin{array}{c}0.35 \\
(0.04)\end{array}$ & $\begin{array}{c}0.36 \\
(0.04)\end{array}$ & $\begin{array}{c}0.42 \\
(0.05)\end{array}$ \\
\hline Add EITC & $\begin{array}{c}0.31 \\
(0.04)\end{array}$ & $\begin{array}{c}0.32 \\
(0.04)\end{array}$ & $\begin{array}{c}0.39 \\
(0.04)\end{array}$ \\
\hline Correct OASDI/SSI & $\begin{array}{c}0.27 \\
(0.04)\end{array}$ & $\begin{array}{c}0.28 \\
(0.04)\end{array}$ & $\begin{array}{c}0.35 \\
(0.04)\end{array}$ \\
\hline Correct Housing Assistance & $\begin{array}{c}0.27 \\
(0.04)\end{array}$ & & $\begin{array}{c}0.34 \\
(0.04)\end{array}$ \\
\hline Correct SNAP & $\begin{array}{c}0.24 \\
(0.04)\end{array}$ & & $\begin{array}{c}0.34 \\
(0.04)\end{array}$ \\
\hline
\end{tabular}

Source: Wave 9 of the 2008 SIPP Panel, spanning January-July 2011. Administrative data sources described in text.

Notes: Standard errors calculated using replicate weights in parentheses. Sample consists of households with at least one member with a PIK and present in reference month 4. Reference month 4 survey weights are adjusted for missing PIKs. In the "Half Minimum Wage" column, half of the federal minimum wage ( $\$ 3.625 /$ hour $)$ is used when correcting wage/salary earnings and self-employment earnings based on reported hours worked (in Table 3, the full federal minimum wage of $\$ 7.25 /$ hour is used in these adjustments). In the "No Housing Assistance" column, housing assistance is not included in the adjustment for in-kind transfers (in Table 3, households that receive housing assistance are removed fromextreme poverty in the in-kind transfer adjustment). In the "\$4/Day" column, households in extreme poverty are those with average incomes across the four months of the wave less than or equal to $\$ 4 /$ person/day. 
Figure 1a. Household Type Distribution of Extreme Poor Subgroups After Adjustments Share of Households

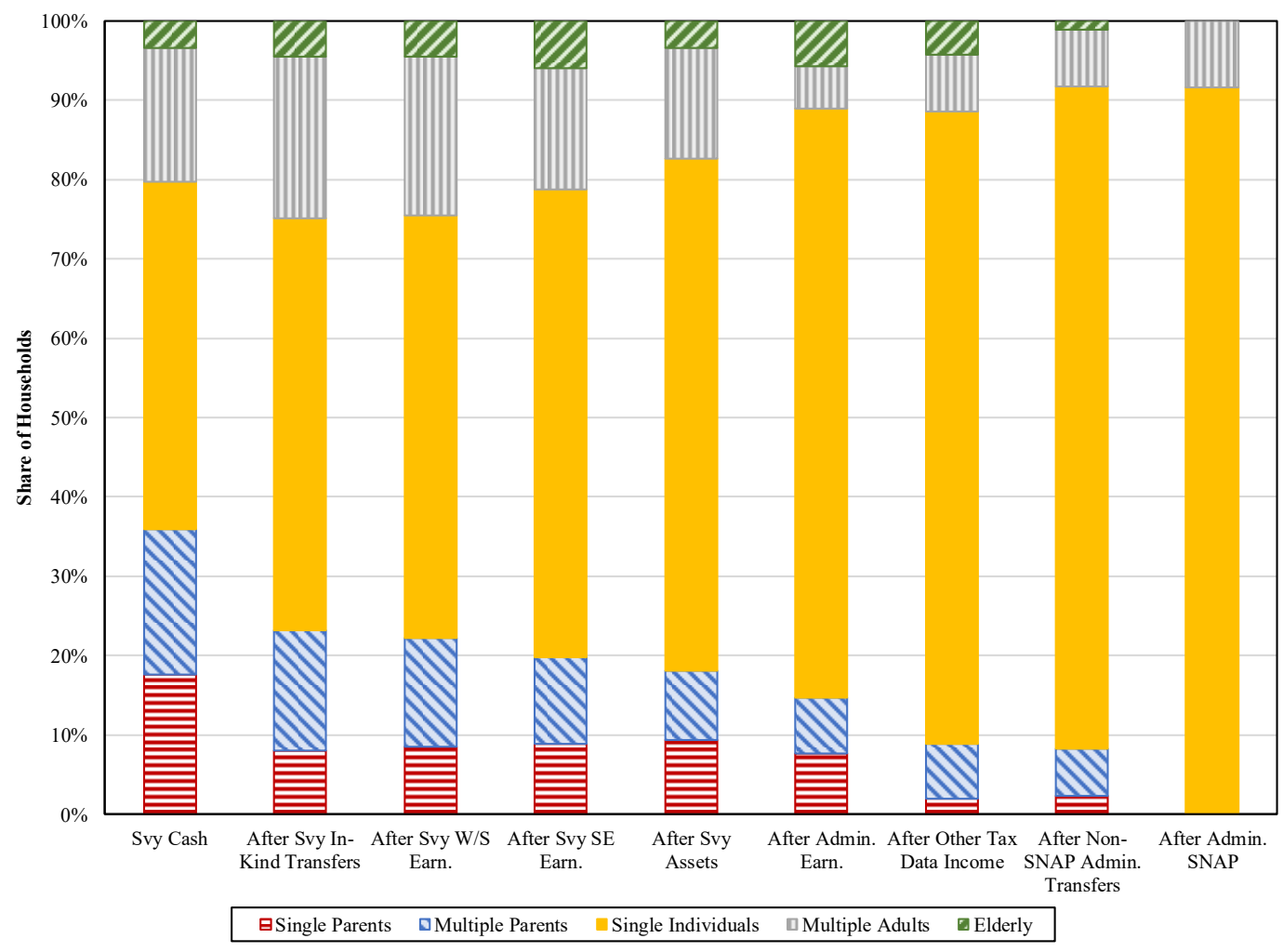

Figure 1b. Household Type Distribution of Extreme Poor Subgroups After Adjustments Share of Individuals

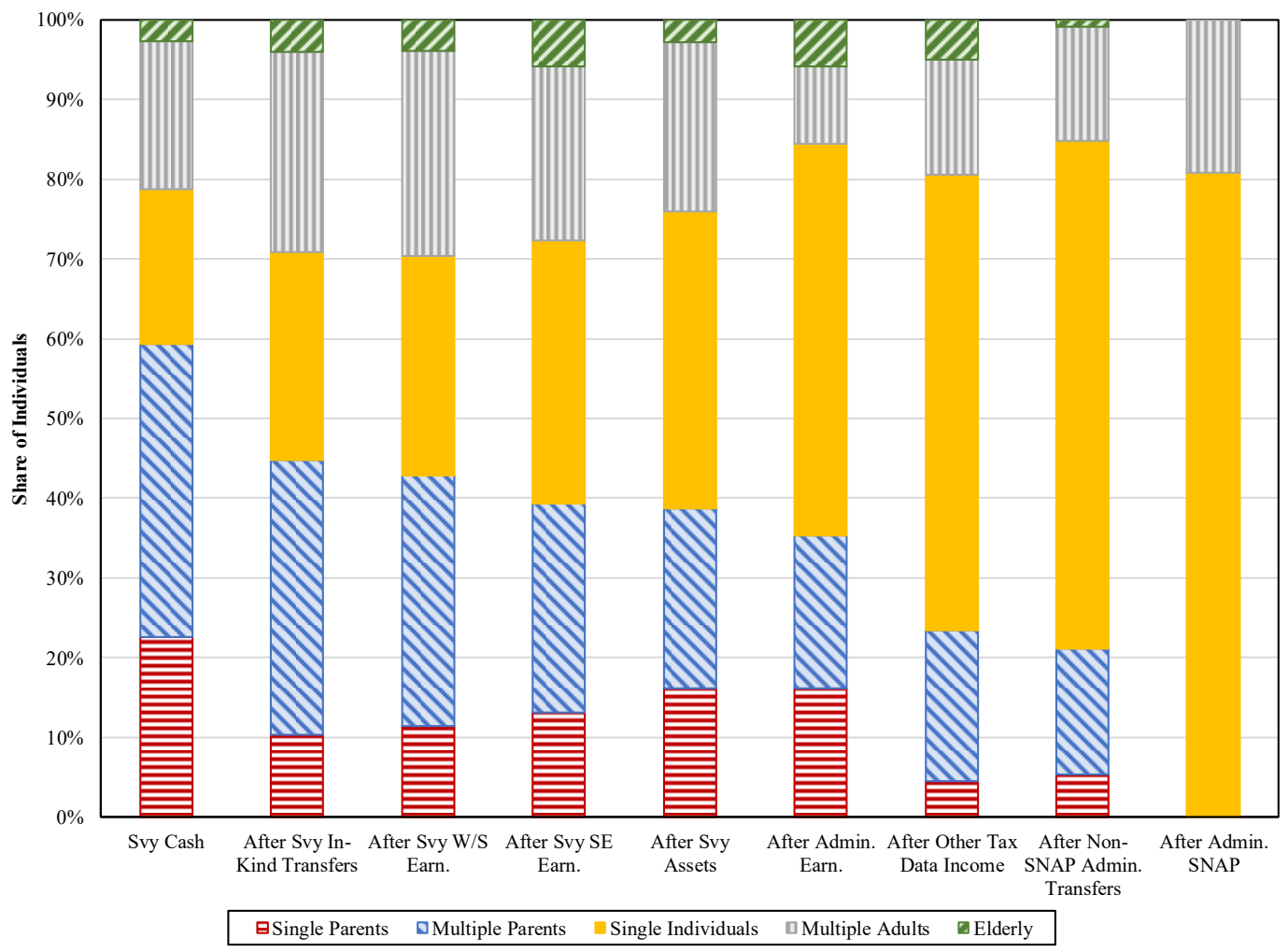

Source: Wave 9 of the 2008 SIPP Panel, spanning January-July 2011. Administrative data sources described in text.

Notes: Sample consists of households with at least one member with a PIK and present in reference month 4 . Reference month 4 survey weights are adjusted for missing PIKs. 
Figure 2. Share of Reported Cash Extreme Poor Households Raised Above Income Thresholds by Administrative Data

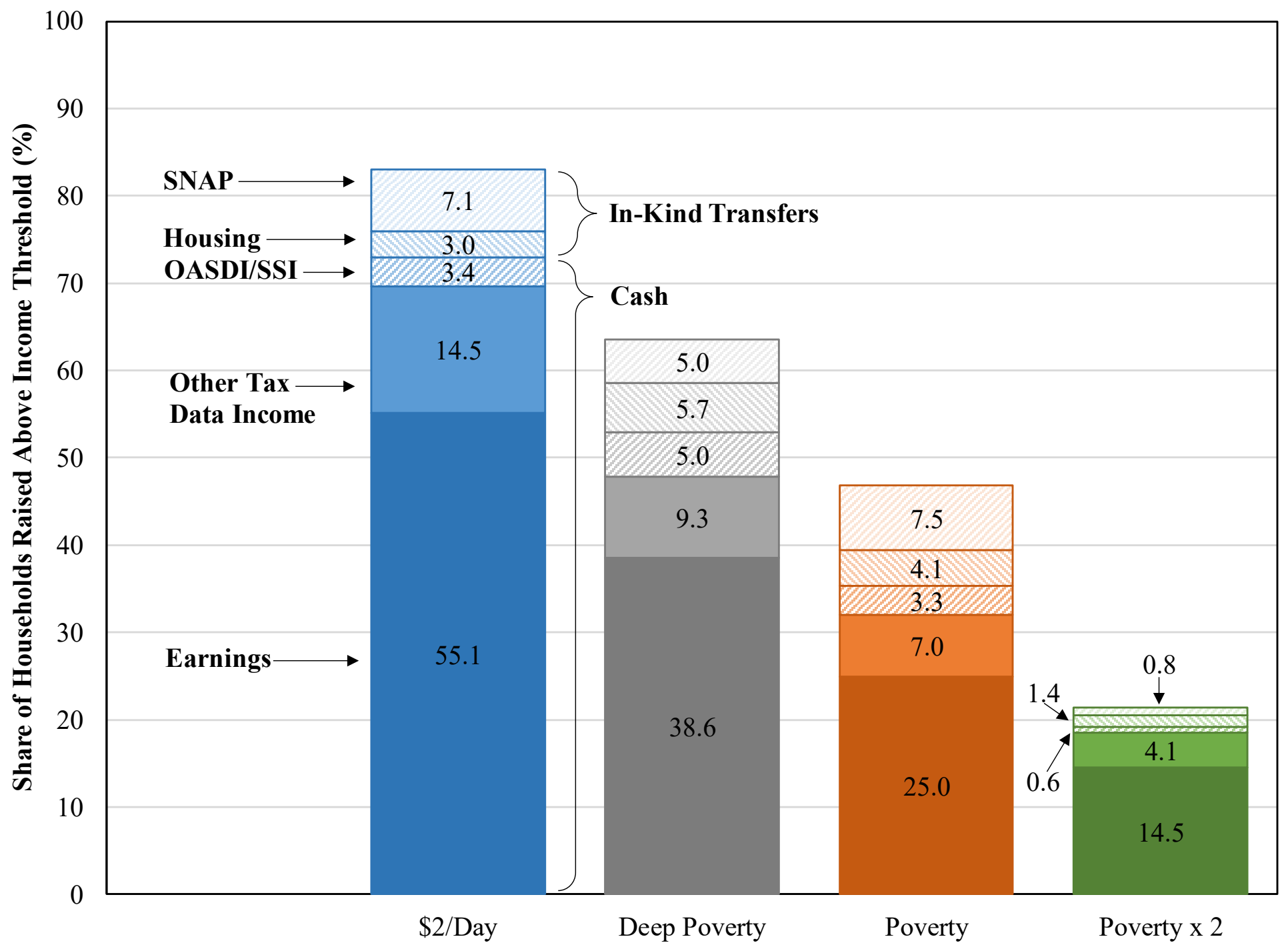

Source: Wave 9 of the 2008 SIPP Panel, spanning January-July 2011. Administrative data sources described in text.

Notes: Sample consists of households with at least one member with a PIK and present in reference month 4 . Reference month 4 survey weights are adjusted for missing PIKs. Other administrative tax data income includes asset income (taxable dividends, taxable and tax-exempt interest), retirement distributions (gross distributions from employer-sponsored plans and IRA withdrawals), and the EITC. 
Figure 3. Share of Households in Extreme Poor Subgroups Raised Above Income Thresholds by Administrative Data

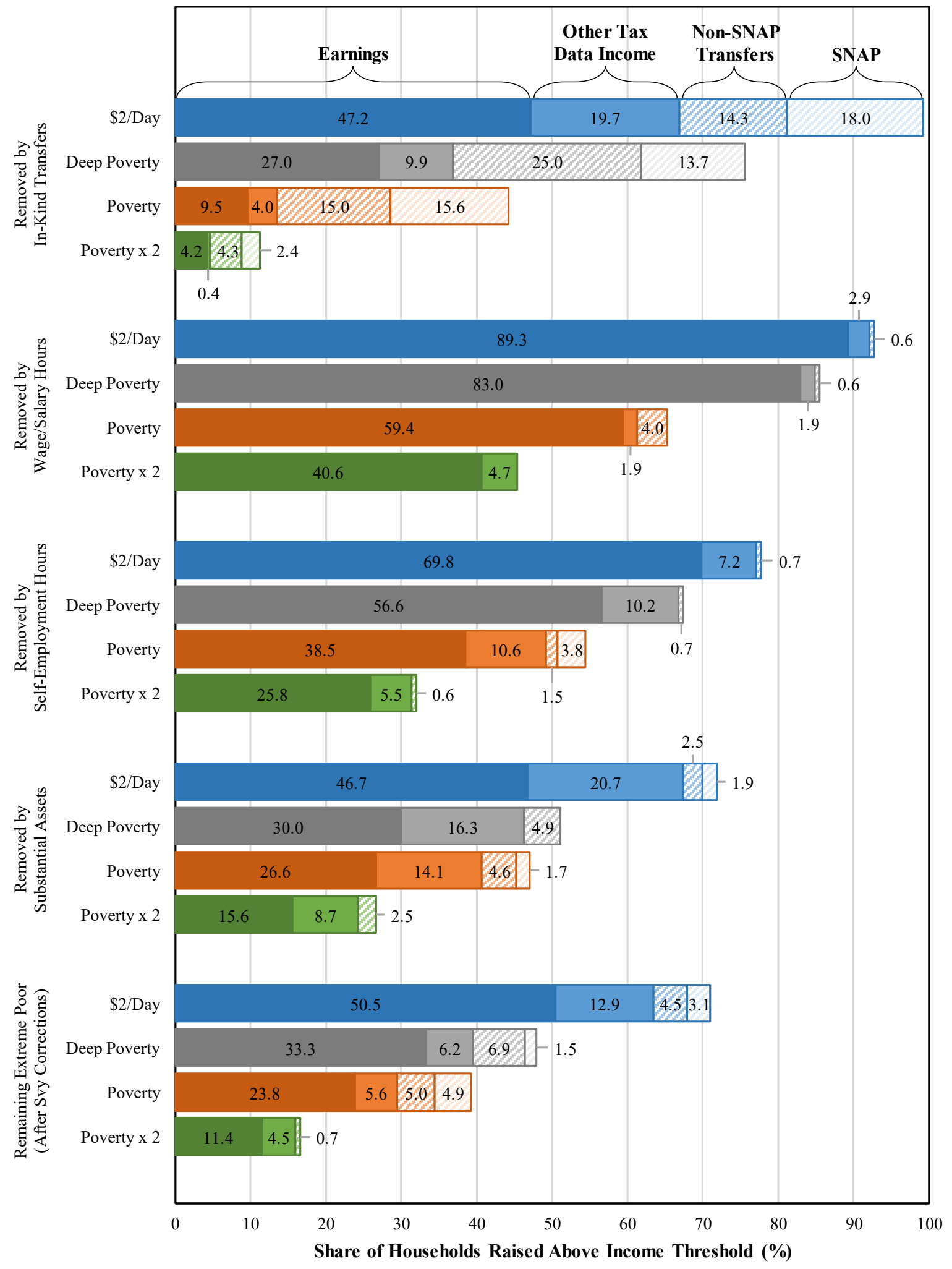

Source: Wave 9 of the 2008 SIPP Panel, spanning January-July 2011. Administrative data sources described in text.

Notes: Sample consists of households with at least one member with a PIK and present in reference month 4. Reference month 4 survey weights are adjusted for missing PIKs. Other administrative tax data income includes asset income (taxable dividends, taxable and tax-exempt interest), retirement distributions (gross distributions from employer-sponsored plans and IRA withdrawals), and EITC. Non-SNAP transfers include OASDI, SSI, and housing assistance. 
Figure 4. Mean Number of Material Hardships for Extreme Poor Subgroups

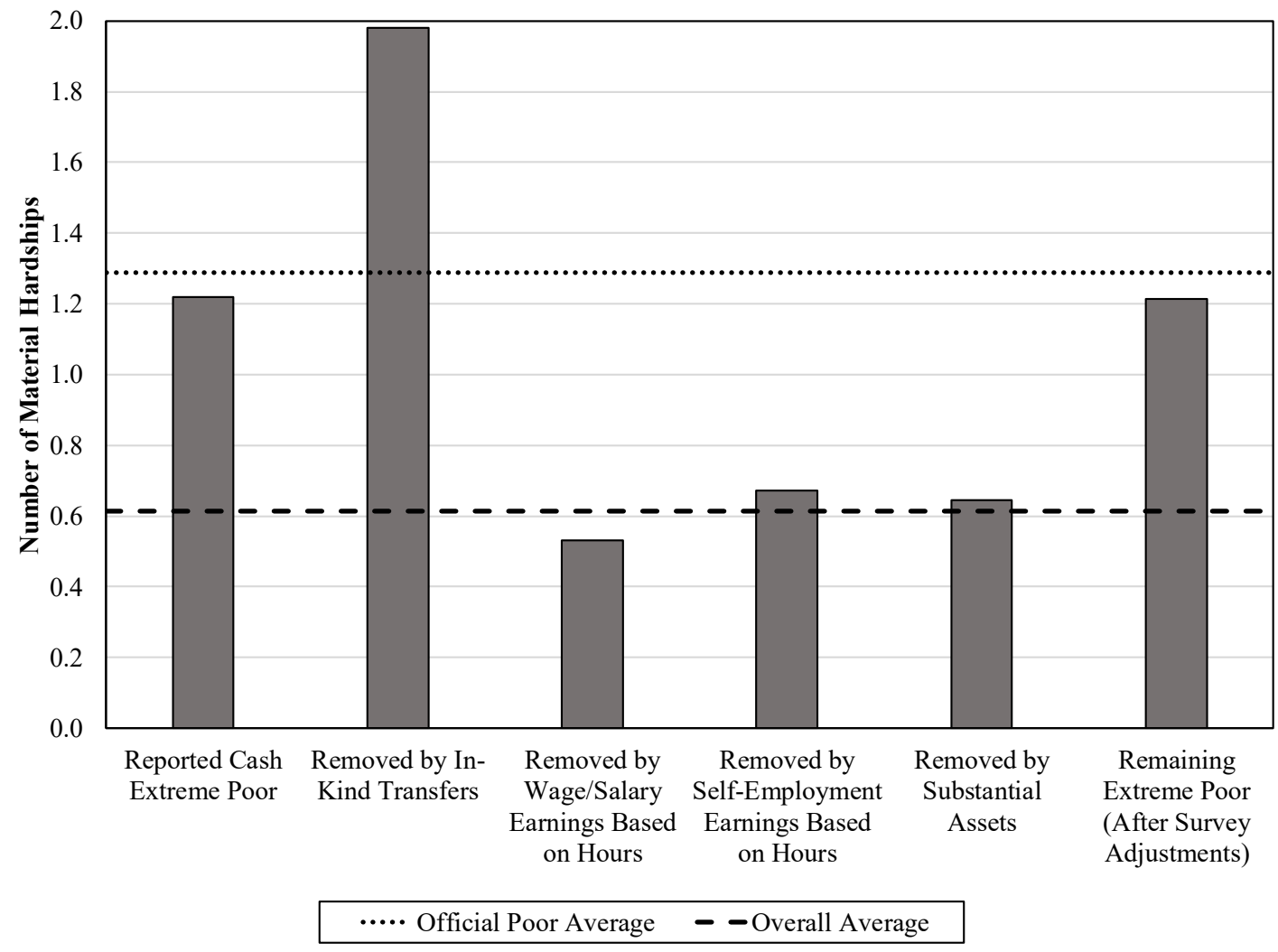

Source: Wave 9 of the public use 2008 SIPP Panel, spanning January-July 2011.

Figure 5. Share of Households with Any Material Hardship for Extreme Poor Subgroups

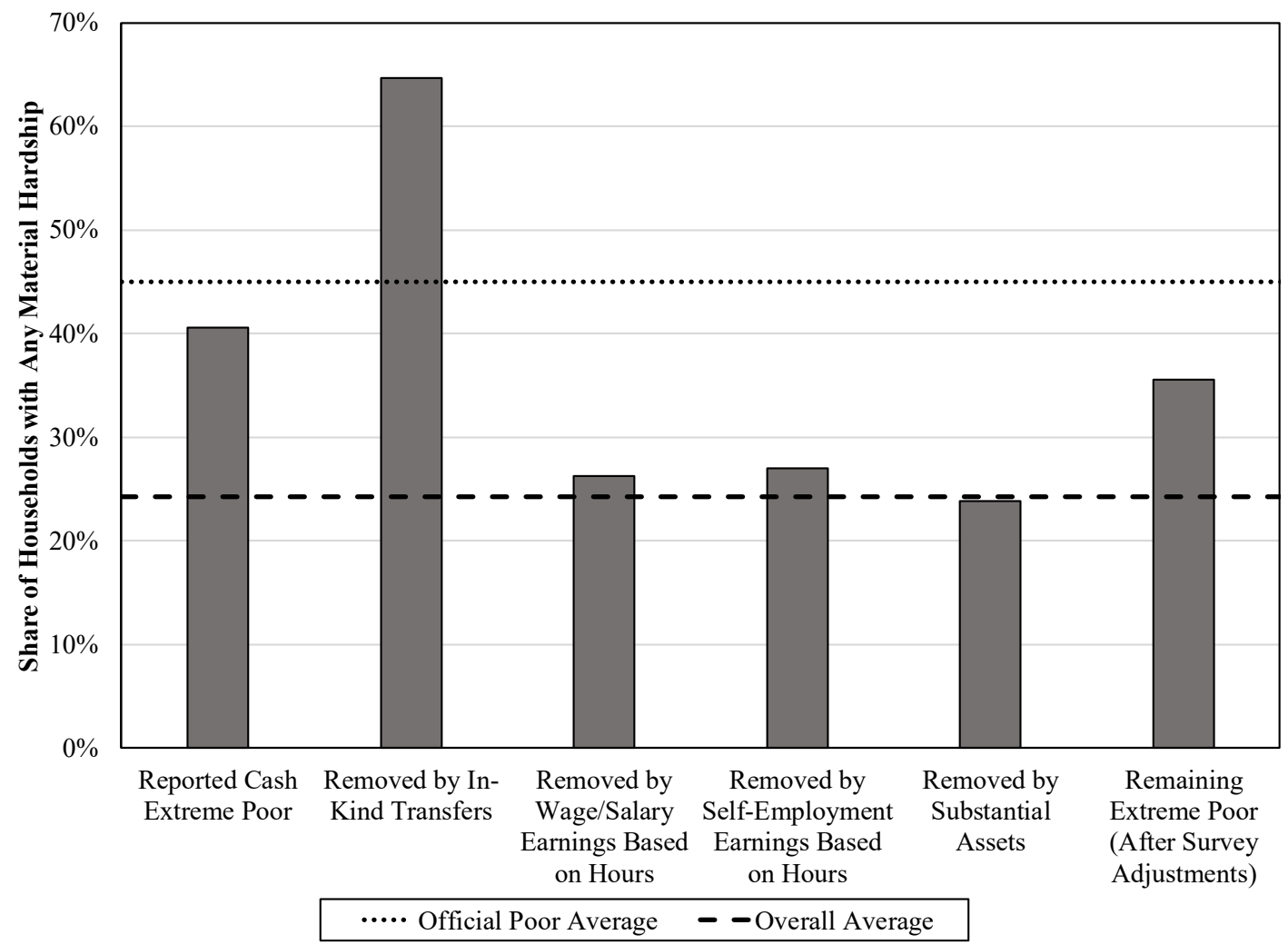

Source: Wave 9 of the public use 2008 SIPP Panel, spanning January-July 2011. 
Figure 6. Mean Number of Home Problems for Extreme Poor Subgroups

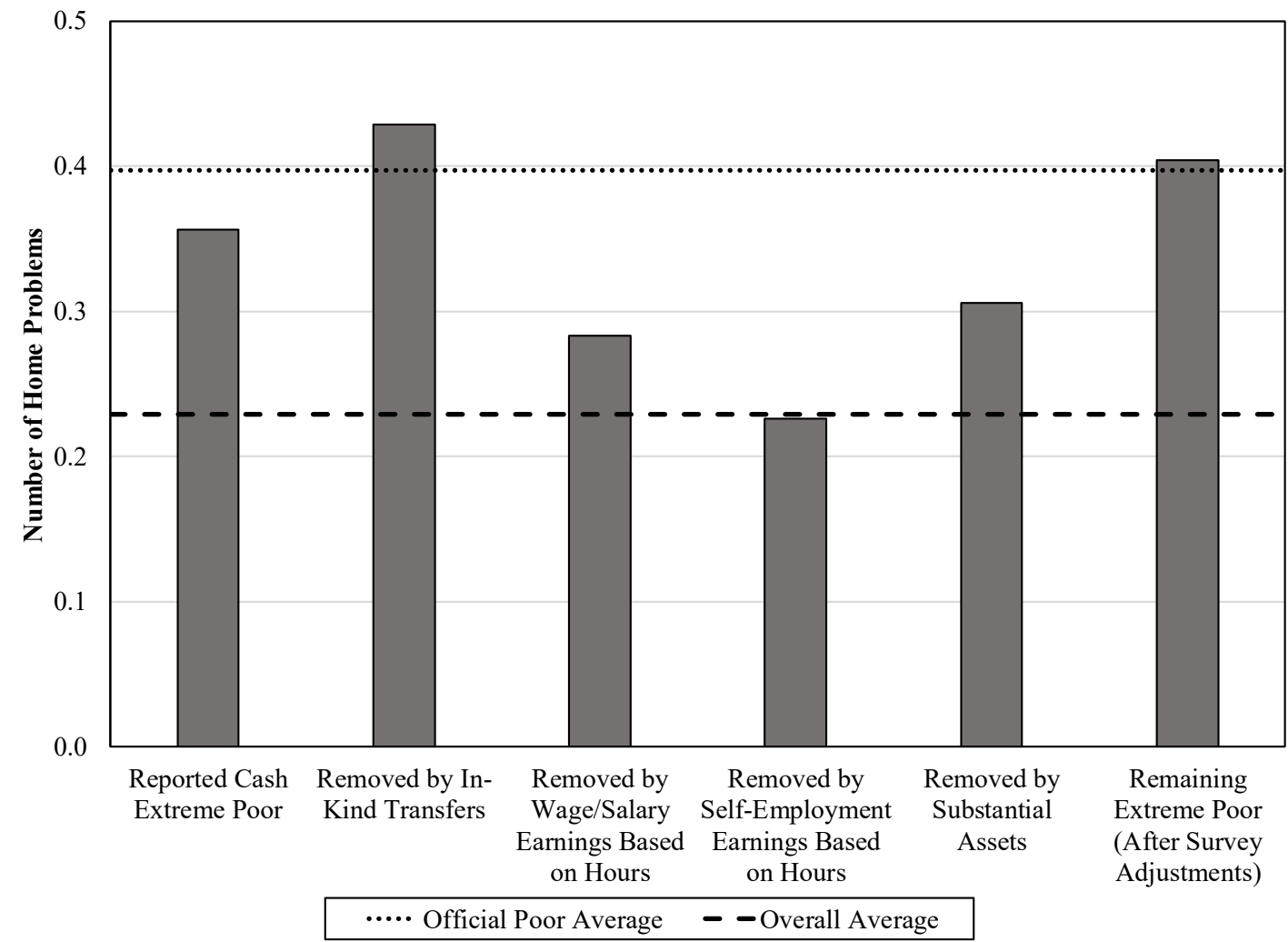

Source: Wave 9 of the public use 2008 SIPP Panel, spanning January-July 2011.

Figure 7. Mean Number of Appliances Owned by Extreme Poor Subgroups

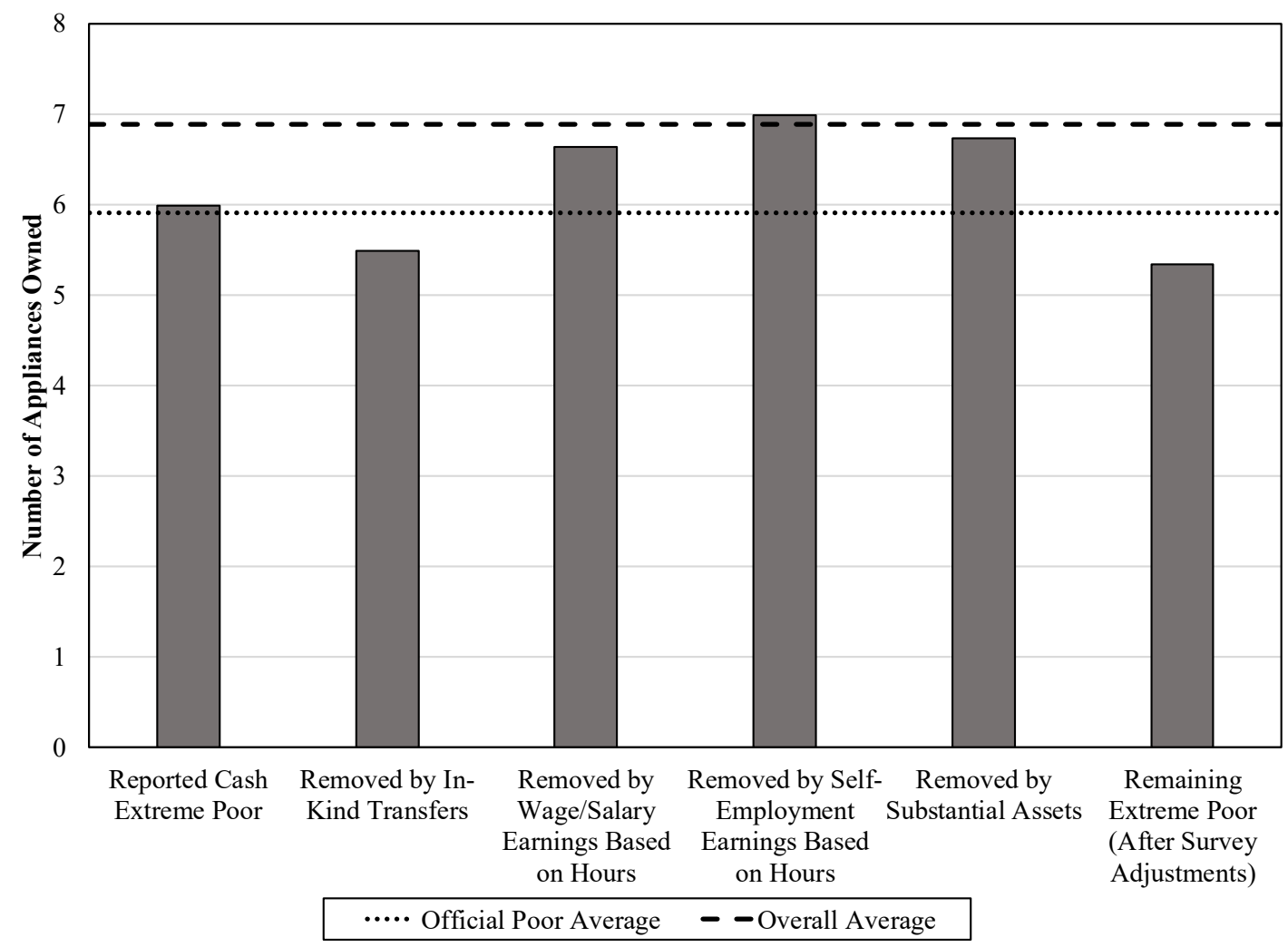

Source: Wave 9 of the public use 2008 SIPP Panel, spanning January-July 2011. 
Figure 8. Expenditures on Four Largest Transfer Programs Not in Administrative Data

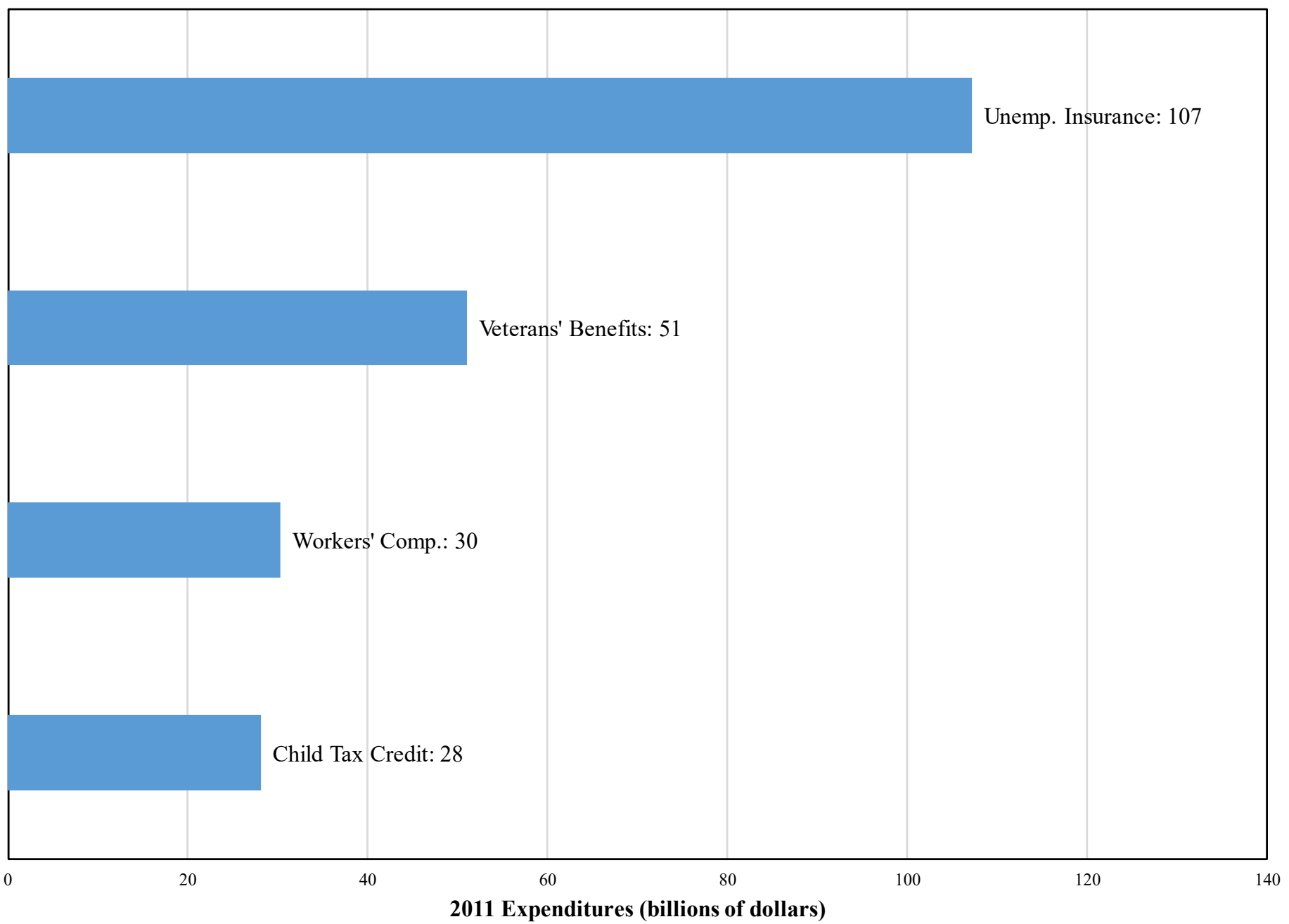

Notes: Does not include Medicare and Medicaid. OASDI, EITC, SSI, housing assistance, and SNAP are in the administrative data. Unemployment insurance, veterans' benefits, workers' compensation, child tax credit, Public Assistance, school food programs, WIC, and LIHEAP are not in the administrative data. Expenditures data from National Income and Product Account Table 3.12 and other sources; see appendix. 